\title{
The non-linear influence of wind-speed variability on gas transfer in lakes
}

\author{
By DAVID M. LIVINGSTONE* and DIETER M. IMBODEN, Umweltphysik, Eidgenössische \\ Technische Hochschule Zürich, EAWAG, CH-8600 Dübendorf, Switzerland
}

(Manuscript received 9 June 1992; in final form 28 September 1992)

\begin{abstract}
The analytical representation of wind-speed probabilities by the Weibull distribution allows the empirical characterization of a scalar wind field on the basis of two Weibull parameters. Such a parameterization obviates the necessity of including wind data in time-series form explicitly in air-water interaction models when accounting for non-linear wind effects. By combining the Weibull wind-speed distribution with commonly employed trilinear and power-law expressions for the dependence of the gas transfer velocity on wind speed, analytical expressions for the mean value of the transfer velocity are obtained. These expressions predict the non-linearity of the dependence of gas transfer velocity on wind speed to be responsible for an increase in the mean transfer velocity which will normally not exceed $100 \%$ of the value obtained when non-linear wind effects are neglected. In the specific case of the winter oxygenation of a typical subalpine Swiss lake (Aegerisee), the commonly employed trilinear and power-law expressions are found to underestimate the mean $\mathrm{O}_{2}$ transfer velocity considerably. It is evident that such expressions cannot be employed to determine gas transfer velocities in sheltered lakes without considerable modification at low wind speeds. The extent of the modification required, however, suggests that the role played by the instantaneous wind speed in determining the gas transfer velocity in such lakes may be much less significant than is usually assumed.
\end{abstract}

\section{Introduction}

Processes involved in promoting or inhibiting the exchange of gases between the atmosphere and a natural water body occur on two sets of space and time scales.

On the microscopic level, at a time $t$ the instantaneous gas flux $F(t)$ per unit time and area across the air-water interface is given by the product of the instantaneous gas transfer velocity $\beta(t)$ and the instantaneous saturation deficit (or excess) $\Delta(t)$ across the interface:

$F(t)=\beta(t) \cdot \Delta(t)$.

This equation, which suffices for the description of

* Corresponding author. gas exchange in most laboratory experiments (e.g., in wind/water tunnels), can also be employed to describe the exchange of gases between the atmosphere and shallow, labile natural water bodies which respond almost immediately to the input of turbulent kinetic energy from the wind by mixing completely on the macroscopic level and in which no concentration gradients exist away from the immediate vicinity of the air-water interface. The rate-limiting step can be thought of as associated with molecular diffusion processes in two zones (air-phase and water-phase) located on either side of the interface. Here we will be concerned solely with the exchange of gases which have a Henry's law constant high enough to render the air-phase resistance negligible compared to the water-phase resistance (about $250 \mathrm{~Pa} \mathrm{~m}^{3} \mathrm{~mol}^{-1}$ according to Mackay, 1985), and for which chemical enhancement effects for water-phase transfer are insignificant (Liss, 1983). 
On the macroscopic level, values of the transfer velocity are often obtained by computing gas fluxes across the air-water interface from changes in the mean gas concentration in a water body. Values of the transfer velocity computed in this way are apparent values: they represent not only a temporal mean, but also a spatial mean over an essentially heterogeneous air-water interface subject to a heterogeneous wind stress. The large-scale vertical mixing processes responsible for transporting dissolved gases towards or away from the airwater interface may represent the rate-limiting step on the macroscopic level. In the case of most deep natural water bodies (e.g., lakes), the time scale associated with such processes is substantially greater than that associated with gas exchange across the air-water interface, and consequently mean gas fluxes and transfer velocities over relatively large time scales are usually of more practical interest than instantaneous values. The relevant equation relating the mean gas flux $\bar{F}$ per unit time and area to the mean transfer velocity $\bar{\beta}$ is:

$$
\begin{aligned}
\bar{F} & =\overline{\beta(t, x, y) \cdot \Delta(t, x, y)} \\
& =\bar{\beta} \cdot \bar{\Delta}+\overline{\beta^{\prime}(t, x, y) \cdot \Delta^{\prime}(t, x, y)},
\end{aligned}
$$

where the instantaneous values $\beta(t, x, y)$ and $\Delta(t, x, y)$ deviate from the corresponding temporal spatial mean values $\bar{\beta}$ and $\bar{\Delta}$ by amounts $\beta^{\prime}(t, x, y)$ and $\Delta^{\prime}(t, x, y)$, respectively, with $\overline{\beta^{\prime}(t, x, y)}=0$ and $\overline{\Delta^{\prime}(t, x, y)}=0$.

The instantaneous gas transfer velocity is dependent on wind speed, but not uniquely so: it is thus not possible to obtain a generally valid, accurate parameterization of the transfer velocity in terms of wind speed alone. Even when other factors are ignored, however, because eq. (2) and not eq. (1) is the equation applicable to most natural water bodies, at least three major complications arise when attempting a macroscopic parameterization of the transfer velocity in terms of wind speed.

(i) The instantaneous gas transfer velocity $\beta$ is not a linear function of wind speed. This implies that the mean transfer velocity $\bar{\beta}$ is a function not only of the mean wind speed, but also of the probability distribution of the wind speed (Wanninkhof et al., 1985, 1987; Boutin and Etcheto, 1991; Wanninkhof, 1992). (ii) In the surface mixed layer of a stratified lake (the epilimnion), concentrations of most environmentally relevant atmospheric gases (e.g., $\mathrm{O}_{2}, \mathrm{CO}_{2}$ ) differ significantly from those in the underlying stratified layer (the metalimnion). Assuming a constant heat balance, an increase in the wind speed will result in an increase in the Monin-Obukhov length of the epilimnion, and consequently in the thickness of the epilimnion at the expense of that of the metalimnion. Thus a wind event will have the effect of increasing or decreasing the mean gas concentration in the epilimnion according to the sign of the concentration gradient at its lower boundary. In both stratified and unstratified lakes, a decrease in the wind speed will cause a decrease in the MoninObukhov length which may result in the formation of a warm (relative to the underlying water), air-saturated surface layer. This will tend to inhibit the exchange of atmospheric gases both directly (since $\Delta \approx 0$ across the interface) and indirectly (by inhibiting vertical mixing). Thus even in nonstratified natural water bodies, $\beta^{\prime}$ and $\Delta^{\prime}$ are likely to be correlated to a certain extent, implying that $\overline{\beta^{\prime} \cdot \Delta^{\prime}} \neq 0$, and the mean gas flux $\bar{F}$ will be determined not only by the mean gas transfer velocity and mean saturation deficit, but also by a nonlinear interaction between transfer velocity and saturation deficit. This process will not affect gas exchange in wind/water tunnels, as the water is likely to be fully mixed regardless of wind speed (the water depth in wind/water tunnel experiments is generally less than $1 \mathrm{~m}$ ).

(iii) The influence of the wind on the gasexchange rate is not direct, but is mediated by wind-induced surface waves and the turbulent structure of the surface water (Hasse and Liss, 1980; Jähne et al., 1987). These mediating factors are spatially heterogeneous and will depend, among other things, on the size and shape of the water body concerned. The degree of spatial heterogeneity of the wind field itself will depend partly on the nature of the surrounding topography. Thus morphological factors specific to the water body under consideration will have an unpredictable influence on local, and hence also on spatially averaged, values of the gas tranfer velocity.

One of the aims of this paper is to investigate 
analytically the effect of the non-linear wind effect (i). Consequently, in order to reduce the effect of the non-linear interaction between transfer velocity and saturation deficit (ii), only homogeneous water bodies will be considered here. The specific case dealt with is that of the increase in the oxygen content of a lake during winter, when the stability of the water column is low. This can be expected to be related to the probability structure of the wind speed over the lake.

The probability structure of a scalar wind field can often be represented satisfactorily in terms of just two parameters, viz. the shape and scale parameters of the Weibull distribution (e.g., Justus et al., 1976). As these parameters describe the longterm behaviour of an important determinant of the lake system, they can themselves be considered to be determinants of the system in their own right and can function as input variables in modelling lake processes (such as gas exchange) which depend in a non-linear fashion on wind speed. This obviates the necessity of including actual wind data in time-series from explicitly in such models, which should help to improve their general applicability.

By combining the Weibull wind-speed distribution with empirical trilinear and power-law relationships between gas transfer velocity and wind speed obtained from the literature, an attempt is made here to obtain analytical expressions for the mean gas transfer velocity $\bar{\beta}$. Such expressions would be of practical use in the prediction of approximate winter oxygenation rates in lakes for which Weibull wind-speed parameters are known or can be determined.

The relevance of this study, however, is not confined to the specific problem of lake oxygenation (the method presented here of computing nonlinear wind effects on gas exchange in lakes may also prove useful in estimating gas exchange rates in oceanic areas), nor is it intended as a discussion of the exact relationship between gas transfer velocity and wind speed. The intention of the authors is rather to attempt to throw some light on the general problem of non-linear wind effects on air-water gas exchange, and, building on this, to discuss the significance of wind speed in promoting gas exchange for the example of a small or medium-sized lake enjoying a certain degree of protection from the wind by virtue of its location in mountainous terrain.

\section{Wind-speed dependence of gas transfer velocity}

Many experimental investigations of the dependence of the gas transfer velocity on wind speed have been carried out in laboratory tanks and wind/water tunnels (Downing and Truesdale, 1955; Kanwisher, 1963; Hoover and Berkshire, 1969; Liss, 1973; Broecker et al., 1978; Münnich et al., 1978; Jähne et al., 1979, 1984a, 1985, 1987; Liss et al., 1981; Merlivat and Memery, 1983; Broecker and Siems, 1984; Wanninkhof and Bliven, 1991), in the ocean (Broecker and Peng, 1974; Peng et al., 1974, 1979; Tsunogai and Tanaka, 1980; Hartmann and Hammond, 1984; Smethie et al., 1985), and in lakes (Peng and Broecker, 1980; Jähne et al., 1984b; Yu et al., 1984; Wanninkhof et al., 1985, 1987, 1990; UpstillGoddard et al., 1990). In part, these experiments have yielded contradictory results, so that the form of the dependence is still the subject of controversy.

\subsection{Wind-speed dependence of gas transfer velocity in the laboratory}

Laboratory experiments by Downing and Truesdale (1955), Kanwisher (1963), Hoover and Berkshire (1969), Liss (1973), Broecker et al. (1978) and Liss et al. (1981) have shown the windspeed dependence of the gas transfer velocity to be slight or non-existent at low wind speeds. Above a certain critical wind speed, however, at which the first appearance of capillary waves is noted, a pronounced wind-speed dependence becomes apparent. The form of this dependence has been suggested to be either quadratic (e.g., Kanwisher, 1963) or linear (e.g., Broecker et al., 1978). In the latter case, neglecting for the moment the effect of bubble entrainment at high wind speeds, the overall dependence of transfer velocity on wind speed may be considered to be approximately bilinear, with an abrupt gradient change at a critical wind speed marking the transition from "smooth" to "rough" surface regimes. A distinct bilinear relationship was found by Münnich et al. (1978) and Jähne et al. (1979) in an annular wind tunnel. Although the magnitude of the critical wind speed was raised to an artificially high level in these experiments due to surface film contamination (Jähne et al., 1984a, 1987), this does not necessarily invalidate the qualitative form of the 
relationship found. Some representative laboratory values for the critical wind speed (neglecting the annular wind-tunnel experiments) are: $\sim 3 \mathrm{~m} \mathrm{~s}^{-1}$ at $5 \mathrm{~cm}$ (Downing and Truesdale, 1955); $\sim 3 \mathrm{~m} \mathrm{~s}^{-1}$ at $10 \mathrm{~cm}$ (Kanwisher, 1963); $\sim 2.5 \mathrm{~m} \mathrm{~s}^{-1}$ at $60 \mathrm{~cm}$ (Broecker et al., 1978) and $\sim 3.5 \mathrm{~m} \mathrm{~s}^{-1}$ at $17 \mathrm{~cm}$ (Liss et al., 1981). Assuming a roughness length of $0.01 \mathrm{~cm}$ (Münnich et al., 1978), the equivalent critical wind speeds at the standard meteorological height of $10 \mathrm{~m}$ would be $\sim 6 \mathrm{~m} \mathrm{~s}^{-1}, \sim 5 \mathrm{~m} \mathrm{~s}^{-1}, \sim 3 \mathrm{~m} \mathrm{~s}^{-1}$ and $\sim 5 \mathrm{~m} \mathrm{~s}^{-1}$, respectively. Emerson (1975), summarizing the results of several laboratory investigations, concluded that wind effects were negligible at wind speeds below $2 \mathrm{~m} \mathrm{~s}^{-1}$ measured at $10 \mathrm{~cm}$, corresponding to $\sim 3 \mathrm{~m} \mathrm{~s}^{-1}$ at $10 \mathrm{~m}$. Thus, despite the fact that it is not possible to give a generally applicable value for the critical wind speed at $10 \mathrm{~m}$ since some degree of dependence on experimental setup is unavoidable, laboratory experiments suggest that it should lie between $3 \mathrm{~m} \mathrm{~s}^{-1}$ and $6 \mathrm{~m} \mathrm{~s}^{-1}$.

\subsection{Wind-speed dependence of gas transfer velocity in the field}

In contrast to experiments in wind/wave tunnels, field experiments on the influence of wind speed on gas transfer velocity have yielded contradictory results. Hasse and Liss (1980) described early field results as "frustrating in that they fail to show a clear dependence on wind speed", Jähne et al. (1984b) remarked that "so far it remains an open question whether a wind speed dependence of gas exchange is real in nature", and Jähne et al. (1985) were of the opinion that gas exchange field data "do not significantly depend on wind speed". Based on GEOSECS data from the Atlantic and Pacific, Peng et al. (1979), for example, could find no relationship between wind and gas exchange. However, the data of Broecker and Peng (1974) from the BOMEX area (N. Atlantic) and Station PAPA (N. Pacific) were considered by them to support Kanwisher's (1963) hypothesis of a quadratic dependence of transfer velocity on wind speed, and Tsunogai and Tanaka (1980) found the dependence observed by them in Funka Bay, Hokkaido, to be quadratic or cubic. Smethie et al. (1985) found a positive correlation between transfer velocity and wind speed in the tropical Atlantic. A linear dependence of transfer velocity on wind speed in the range $3.2 \mathrm{~m} \mathrm{~s}^{-1}<v<6.4 \mathrm{~m} \mathrm{~s}^{-1}$ ( $v=$ wind speed at $10 \mathrm{~m}$ ) was found by Hartmann and Hammond (1984) in San Francisco Bay. For lakes, Örn (1980) showed the increase in hypolimnetic $\mathrm{O}_{2}$ in Lake Zürich during winter to be dependent on wind speeds greater than $20 \mathrm{~km} \mathrm{~h}^{-1}$ $\left(5.6 \mathrm{~m} \mathrm{~s}^{-1}\right)$, and Jähne et al. (1984b) found a significant wind-speed dependence of the He transfer velocity in four other Swiss lakes. In Spruce Run Reservoir, New Jersey, Yu et al. (1984) found no wind influence on the $\mathrm{O}_{2}$ transfer velocity at wind speeds less than 2 to $4 \mathrm{~m} \mathrm{~s}^{-1}$, a linear dependence between 2 to $4 \mathrm{~m} \mathrm{~s}^{-1}$ and 6 to $7 \mathrm{~m} \mathrm{~s}^{-1}$ and a non-linear dependence between 6 to $7 \mathrm{~m} \mathrm{~s}^{-1}$ and $15 \mathrm{~m} \mathrm{~s}^{-1}$. Recent results using the tracer $\mathrm{SF}_{6}$ in lakes support the hypothesis of a strong wind-speed dependence of gas transfer velocity at intermediate wind speeds (Wanninkhof et al., 1985, 1987, 1990; Upstill-Goddard et al., 1990). Wanninkhof et al. (1985) found the $\mathrm{SF}_{6}$ transfer velocity in Rockland Lake, New York, to be linearly dependent on wind speed at wind speeds exceeding $2.4 \mathrm{~m} \mathrm{~s}^{-1}$ measured at $1 \mathrm{~m}$, corresponding to $\sim 4 \mathrm{~m} \mathrm{~s}^{-1}$ at $10 \mathrm{~m}$. Wanninkhof et al. (1987) found the $\mathrm{SF}_{6}$ transfer velocity in two Californian lakes to be strongly dependent on wind speed in the range $2 \mathrm{~m} \mathrm{~s}^{-1} \leqslant v \leqslant 5 \mathrm{~m} \mathrm{~s}^{-1}$, and suggested using a bilinear relationship with a gradient discontinuity at about $3.5-4 \mathrm{~m} \mathrm{~s}^{-1}$ to describe this dependence. Upstill-Goddard et al. (1990) used a bilinear dependence of transfer velocity on wind speed with a gradient discontinuity at $v=9.5 \mathrm{~m} \mathrm{~s}^{-1}$ to fit their $\mathrm{SF}_{6}$ data from two small Cornish lakes. Wanninkhof et al. (1990) used a power-law relationship with exponent 1.64 to fit data from $\mathrm{SF}_{6}$ experiments in five North American lakes, while at the same time drawing attention to the uncertainty inherent in their relationship.

It is obvious from the above discrepancies that, although a wind-speed dependence of the gas transfer velocity can be assumed to exist in both maritime and lacustrine environments, no one relationship between transfer velocity and wind speed exists which is valid for all laboratory and field situations. This is not surprising in view of the fact that wind speed is not the only parameter controlling mass transfer across the air-water interface. According to Jähne et al. (1987), for instance, different wave fields may change the gas exchange rate by a factor of four. Broecker et al. (1978) have questioned whether wave spectra similar to those 
existing under natural conditions can develop at all in small laboratory tanks, and, according to Hasse (1990), secondary flows in laboratory experiments force some type of surface renewal not characteristic of conditions existing in natural water bodies. In natural water bodies, especially at low wind speeds, buoyancy-driven convection due to surface cooling may contribute to gas exchange. Quinn and Otto (1971) and Münnich et al. (1978) have mentioned the possibility that evaporation at the interface may enhance gas exchange in this way. Liss et al. (1981) have shown that, although the effect of evaporation on gas exchange appears to be negligible, condensation can cause a $30 \%$ reduction in the $\mathrm{O}_{2}$ transfer velocity, suggesting that fluctuations in relative humidity and air temperature may affect gas transfer velocities. Marti and Imboden (1986) have shown that short-term fluctuations in relative humidity have a considerable effect on heat exchange at the lake surface. Thus relative humidity, mediated by its effect on the turbulent structure of the surface layer, may be an important factor in determining gas exchange. In addition, in contrast to the situation pertaining in the laboratory, the turbulent structure of natural water bodies is influenced by non-local spatial and temporal effects (e.g., by the lateral transport of turbulent kinetic energy and by its storage in the form of internal and surface waves), and thus gas exchange between the atmosphere and natural water bodies cannot be considered a point phenomenon. Although this applies to the ocean as well as lakes, edge effects and the topographically induced spatial heterogeneity of the wind field may result in an even greater discrepancy between field and laboratory results in the case of inland waters than in the case of the open ocean. Taking the above factors into consideration, it is obvious that a generally valid accurate parameterization of the gas transfer velocity cannot be obtained in terms of wind speed alone. Nevertheless both laboratory and field studies show the wind-speed dependence of the gas transfer velocity to be slight at low wind speeds and substantially greater at wind speeds exceeding about 3 to $6 \mathrm{~m} \mathrm{~s}^{-1}$. A bilinear relationship would at first sight appear to be the simplest and best method of parameterizing this dependence, at least up to the point where breaking gravity waves cause a further qualitative change in the processes affecting gas exchange.

\subsection{Influence of bubble injection}

Merlivat and Memery (1983) have emphasized the importance of bubble injection from breaking gravity waves in enhancing the uptake of atmospheric gases at high wind speeds. Broecker and Siems (1984) observed a sudden increase in transfer velocity in the case of oxygen desorption in a wind-tunnel at a wind speed of $10 \mathrm{~m} \mathrm{~s}^{-1}$, and Thorpe (1982) found the influence of bubble injection on gas exchange in Loch Ness to be significant only at wind speeds exceeding $12 \mathrm{~m} \mathrm{~s}^{-1}$, a conclusion supported by work on bubble injection in wind/water tunnels by Jähne et al. (1985). The $\mathrm{SF}_{6}$ lake data of Upstill and Goddard (1990) imply a somewhat lower value of this critical wind speed $\left(\sim 9.5 \mathrm{~m} \mathrm{~s}^{-1}\right)$. In order to take account of bubble injection at high wind speeds, Liss and Merlivat (1986) suggested adding a third straight-line segment to the bilinear relationship between transfer velocity and wind speed to cover wind speeds exceeding $13 \mathrm{~m} \mathrm{~s}^{-1}$. As wind speeds of the magnitude required to induce wave breaking are only rarely encountered in central Europe (e.g., during extreme Föhn conditions), the contribution of bubble injection to gas exchange in lakes situated in this region of the world can probably be safely neglected. However, in order to avoid loss of generality, the full trilinear relationship of Liss and Merlivat (1986) will be retained here.

\subsection{The trilinear and power-law relationships between gas transfer velocity and wind speed}

The trilinear Liss-Merlivat relationship is frequently employed in the estimation of oceanatmosphere $\mathrm{CO}_{2}$ exchange (e.g., Etcheto and Merlivat, 1988; Etcheto et al., 1991; Inoue and Sigimura, 1992) and has also been incorporated into oceanic $\mathrm{O}_{2}$ models (Spitzer and Jenkins, 1989). Erickson (1989) based his computation of the global transfer velocity field for $\mathrm{CO}_{2}$ on this relationship. Data from an $\mathrm{SF}_{6} /{ }^{3} \mathrm{He}$ experiment conducted in the ocean have been found to support the Liss-Merlivat relationship at high and intermediate oceanic wind speeds (Watson et al., 1991), but verification of the relationship at low wind speeds is lacking.

In the following, $v$ denotes measured wind speed ( $10 \mathrm{~m}$ above the water surface), $v_{\mathrm{a}}$ the critical wind speed at which capillary waves first appear, and $v_{\mathrm{b}}$ the critical wind speed at which gravity waves 
begin to break. Regimes I $\left(v \leqslant v_{\mathrm{a}}\right)$, II $\left(v_{\mathrm{a}}<v \leqslant v_{\mathrm{b}}\right)$ and III $\left(v>v_{\mathrm{b}}\right)$ in Fig. 1 refer to the "smooth surface", "rough surface" and "breaking wave" regimes of Liss and Merlivat (1986), respectively. The general trilinear relationship between gas transfer velocity $\beta$ and wind speed $v$ can be expressed as follows:

$\beta= \begin{cases}p_{1}+q_{1} v & \text { Regime I } \\ p_{2}+q_{2} v & \text { Regime II } \\ p_{3}+q_{3} v & \text { Regime III. }\end{cases}$

The critical velocities ( $10 \mathrm{~m}$ above the water surface) according to Liss and Merlivat (1986) are $v_{\mathrm{a}}=3.6 \mathrm{~m} \mathrm{~s}^{-1}$ and $v_{\mathrm{b}}=13 \mathrm{~m} \mathrm{~s}^{-1}$. Conversion of the values of the coefficients of eq. (3) as proposed by Liss and Merlivat (1986) for $\mathrm{CO}_{2}$ at $20^{\circ} \mathrm{C}$ (i.e., for a Schmidt number $\mathrm{Sc}=600$ ) to those applicable to $\mathrm{O}_{2}$ at $4^{\circ} \mathrm{C}$ (i.e., $\mathrm{Sc}=1242$ ) is carried out under the assumption that $\beta \propto \mathrm{Sc}^{-2 / 3}$ for $v \leqslant v_{\mathrm{a}}$ and $\beta \propto \mathrm{Sc}^{-1 / 2}$ for $v>v_{\mathrm{a}}$ (Jähne et al., 1984a; Ledwell, 1984) by multiplying by a factor of $(1242 / 600)^{-2 / 3}=0.616$ for $v \leqslant 3.6 \mathrm{~m} \mathrm{~s}^{-1}$ and $(1242 / 600)^{-1 / 2}=0.695$ for $v>3.6 \mathrm{~m} \mathrm{~s}^{-1}$. The values of the coefficients for both Schmidt numbers are listed in Table 1. (This approach has one slight blemish which, although of little practical significance in view of the other uncertainties involved, should be mentioned here: the employment of two different Schmidt number dependences with an abrupt transition between them must result in a discontinuity in $\beta(v)$ at $v=v_{\mathrm{a}}$ when converting between Schmidt numbers. This is of course true regardless of the form of the function $\beta(v)$, but is perhaps more easily overlooked in the case of a multilinear function than, say, in the case of a polynomial. The discontinuity can be removed by allowing a certain degree of dependence of $v_{a}$ on Sc.)

A more convenient form of the general trilinear relationship (eq. 3 ) for our purposes is:

$$
\beta= \begin{cases}\beta_{0} & v=0 \\ \beta_{0}+q_{1} v & \text { Regime I } \\ \beta_{0}+q_{1} v_{\mathrm{a}}+q_{2}\left(v-v_{\mathrm{a}}\right) & \text { Regime II } \\ \beta_{0}+q_{1} v_{\mathrm{a}}+q_{2}\left(v_{\mathrm{b}}-v_{\mathrm{a}}\right) & \\ \quad+q_{3}\left(v-v_{\mathrm{b}}\right) & \text { Regime III }\end{cases}
$$

where $\beta_{0}\left(\equiv p_{1}\right)$ is the wind-independent (minimum) transfer velocity at $v=0$, set to zero by Liss and Merlivat (1986).
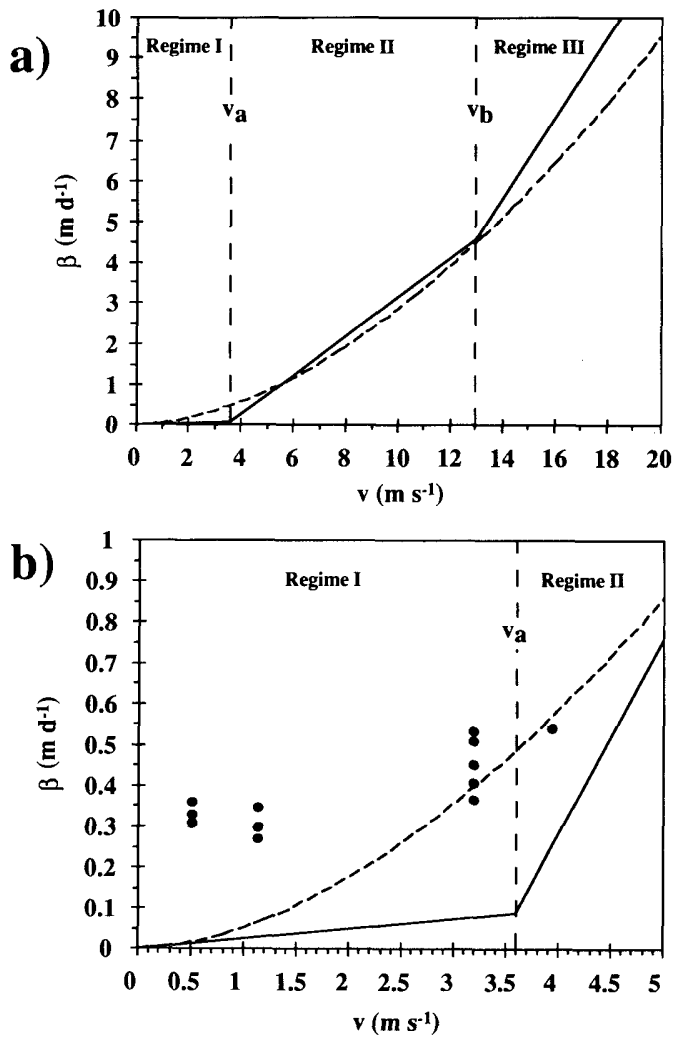

Fig. 1. The dependence of the gas transfer velocity $\beta$ (converted to $\mathrm{O}_{2}$ at $4^{\circ} \mathrm{C}$, i.e., to a Schmidt number Sc of 1242 ) on wind speed $v$ (at a height of $10 \mathrm{~m}$ ) according to Liss and Merlivat (1986) (trilinear relationship, eqs. (3) and (4), solid line) and Wanninkhof and Bliven (1991) (power-law relationship, eq. (5), dashed line), respectively. Wind-speed regimes I, II and III, separated by critical wind speeds $v_{\mathrm{a}}$ and $v_{\mathrm{b}}$, refer to the "smooth surface", "rough surface" and "breaking wave" regimes, respectively, of Liss and Merlivat (1986). The relationships are illustrated for wind-speed ranges of $0-20 \mathrm{~m} \mathrm{~s}^{-1}$ (a) and $0-5 \mathrm{~m} \mathrm{~s}^{-1}$ (b). Laboratory data measured by Liss et al. (1981) at low wind speeds (converted to $\mathrm{Sc}=1242$ ) are represented in (b) by solid circles.

In contrast to the trilinear relationship, several investigators (e.g., Hartman and Hammond, 1984; Yu et al., 1984; Wanninkhof et al., 1991; Wanninkhof and Bliven, 1991) have suggested relating gas transfer to wind speed using a powerlaw dependence across the whole range of wind speeds. This type of relationship can be expressed as follows:

$\beta=\beta_{0}+r v^{n}$, 
Table 1. Values of the coefficients of the trilinear relationship (eq. (3)) as given by Liss and Merlivat (1986) for $\mathrm{CO}_{2}$ at $20^{\circ} \mathrm{C}(\mathrm{Schmidt}$ number $\mathrm{Sc}=600)$, and converted to $\mathrm{O}_{2}$ at $4^{\circ} \mathrm{C}(\mathrm{Sc}=1242)$

\begin{tabular}{ccccccc}
\hline $\mathrm{Sc}$ & $\begin{array}{c}p_{1} \\
\left(\mathrm{~m} \mathrm{~d}^{-1}\right)\end{array}$ & $\begin{array}{c}p_{2} \\
\left(\mathrm{~m} \mathrm{~d}^{-1}\right)\end{array}$ & $\begin{array}{c}p_{3} \\
\left(\mathrm{~m} \mathrm{~d}^{-1}\right)\end{array}$ & $\begin{array}{c}q_{1} \\
\left(\mathrm{~m} \mathrm{~d}^{-1} / \mathrm{m} \mathrm{s}^{-1}\right)\end{array}$ & $\begin{array}{c}q_{2} \\
\left(\mathrm{~m} \mathrm{~d}^{-1} / \mathrm{m} \mathrm{s}^{-1}\right)\end{array}$ & $\begin{array}{c}q_{3} \\
\left(\mathrm{~m} \mathrm{~d}^{-1} / \mathrm{m} \mathrm{s}^{-1}\right)\end{array}$ \\
\hline 600 & 0 & -2.32 & -11.83 & 0.041 & 0.684 & 1.416 \\
1242 & 0 & -1.61 & -8.22 & 0.025 & 0.475 & 0.984 \\
\hline
\end{tabular}

where the constant term $\beta_{0}$ again accounts for the possibility of a non-zero gas exchange rate at zero wind speed. Based on results from the large Delft wind-wave tank, Wanninkhof and Bliven (1991) obtained a value of 1.73 for the exponent $n$ with $\beta_{0}=0$. If $\beta$ is in $\mathrm{m} \mathrm{d}^{-1}$ and $v$ is in $\mathrm{m} \mathrm{s}^{-1}, \mathrm{r}$ takes on the value 0.0768 for $\mathrm{CO}_{2}$ at $20^{\circ} \mathrm{C}(\mathrm{Sc}=600)$, giving $r=0.0534$ for $\mathrm{O}_{2}$ at $4^{\circ} \mathrm{C} \quad(\mathrm{Sc}=1242)$, assuming $\beta \propto \mathrm{Sc}^{-1 / 2}$.

As far as practical applicability is concerned, there is probably little to choose between the Liss-Merlivat (L-M) and Wanninkhof-Bliven (W-B) relationships at wind speeds exceeding about $5 \mathrm{~m} \mathrm{~s}^{-1}$, although the predicted transfer velocities do diverge somewhat at wind speeds above about $13 \mathrm{~m} \mathrm{~s}^{-1}$ (Fig. 1a). Within the range $5 \mathrm{~m} \mathrm{~s}^{-1} \leqslant v \leqslant 13 \mathrm{~m} \mathrm{~s}^{-1}$, the two relationships are found to agree very well and both give a good functional representation of the results obtained to date from laboratory and field research in this range. Below about $5 \mathrm{~m} \mathrm{~s}^{-1}$, i.e., within the range of surface wind speeds most frequently found over land (and consequently over most inland waters), there is, however, a marked disagreement over the form of the relationship (Fig. 1b). At a wind speed of $2 \mathrm{~m} \mathrm{~s}^{-1}$, for example, the $\mathrm{L}-\mathrm{M}$ relationship predicts the $\mathrm{O}_{2}$ transfer velocity at $4^{\circ} \mathrm{C}$ to be $0.05 \mathrm{~m} \mathrm{~d}^{-1}$, whereas the $\mathrm{W}-\mathrm{B}$ relationship predicts a value of $0.18 \mathrm{~m} \mathrm{~d}^{-1}$. This discrepancy reflects the lack of data on gas exchange available at low wind speeds. Those data which are available, however, suggest that actual transfer velocities at low wind speeds may be higher than those predicted by either of the two relationships. At zero wind speed, Downing and Truesdale (1955) found a transfer velocity of $0.36 \mathrm{~m} \mathrm{~d}^{-1}$ for $\mathrm{O}_{2}$ at $20^{\circ} \mathrm{C}(\mathrm{Sc}=490)$, corresponding to $0.23 \mathrm{~m} \mathrm{~d}^{-1}$ at $4^{\circ} \mathrm{C}$. Liss et al. (1981) found the transfer velocity for $\mathrm{O}_{2}$ at $15^{\circ} \mathrm{C}$ $(\mathrm{Sc}=643)$ to be as high as $0.48 \mathrm{~m} \mathrm{~d}^{-1}$ at a friction velocity of $0.0176 \mathrm{~m} \mathrm{~s}^{-1}$; this corresponds to a transfer velocity of $0.35 \mathrm{~m} \mathrm{~d}^{-1}$ for $\mathrm{O}_{2}$ at $4^{\circ} \mathrm{C}$ at a wind speed $v \approx 0.5 \mathrm{~m} \mathrm{~s}^{-1}$ (Fig. 1b).

\section{Parameterization of wind speed using the Weibull distribution}

Wind speed is normally incorporated into airwater interaction models explicitly in time-series form. Although this allows the applicability of a given relationship between gas transfer velocity and wind speed to be tested for specific field data sets, such an approach cannot yield any information on the general applicability of the relationship in the field. In order to obtain information of this kind, the wind-speed data must be represented in a more mathematically tractable form, for instance in terms of an analytical probability distribution function. Combining such a function with a function describing the dependence of the gas transfer velocity on the instantaneous wind speed would yield an analytical probability distribution function for the gas transfer velocity. This would allow computation of a mean gas transfer velocity, which for the macroscopic field situation (eq. (2)) is of more interest than instantaneous values.

The two-parameter Weibull distribution (Weibull, 1951) is often used to describe the cumulative frequency distribution of wind speeds analytically (e.g., Davenport, 1967; Orlenko, 1968; Justus et al., 1976, 1978; Hennessey, 1977; Conradsen et al., 1984; Pavia and O'Brien, 1986). It is more flexible than the log-normal distribution, which has been used for the same purpose (Luna and Church, 1974), and, according to a comparative study of the two analytical distributions for the description of wind-speed data (Justus et al., 1976), yields lower errors than the latter. A further comparative study by Justus et al. (1978) has also demonstrated the superiority of Weibull methods over Widger's (1977) square-root-normal method. Thus the Weibull distribution was chosen as suitable for this study. Conceptually, however, the exact analytical form of the function chosen is not important.

For the purposes of this study it was not judged 
necessary to employ either of the two more complex versions of the Weibull distribution sometimes used to account for lack of anemometer response at low wind speeds; viz. the three-parameter Weibull distribution preferred by Stewart and Essenwanger (1978) and by Van der Auwera et al. (1980), or the hybrid Weibull distribution of Takle and Brown (1978). A comparative study by Tuller and Brett (1984) concluded that the advantage to be gained by using either of these more complex versions instead of the ordinary two-parameter Weibull distribution is slight. Tuller and Brett (1984) have also provided a partial theoretical justification of the use of the Weibull distribution in wind-speed work. In spite of the proven general suitability of the Weibull distribution for the description of wind-speed data, Erickson and Taylor (1989), in a study of model-generated global wind fields, have nevertheless shown that a large proportion of surface wind-speed frequency distributions $(29 \%$ to $35 \%)$ are non-Weibull in character. The suitability of the Weibull distribution to describe a particular wind field must therefore be established for each specific case.

The cumulative two-parameter Weibull distribution $F(v)$ is given by:

$F(v)=\exp -\left(\frac{v}{\eta}\right)^{\xi}$

$F(v)$ is the probability of a measured wind speed exceeding a given value $v$. The form of the distribution curve is determined by the shape parameter $\xi$ (e.g., $\xi=1$ yields an exponential distribution, $\xi=2$ a Rayleigh distribution); the scale of the $v$-axis is determined by the scale parameter $\eta$. The negative derivative of $F(v)$ yields the corresponding probability density function $f(v)$ :

$f(v)=\frac{\xi}{v}\left(\frac{v}{\eta}\right)^{\xi} \exp -\left(\frac{v}{\eta}\right)^{\xi}$

The mean $(\mu)$ and variance $\left(\sigma^{2}\right)$ associated with the Weibull distribution (see for example Ravenis, 1964, or Justus et al., 1976) are given by:

$$
\begin{aligned}
& \mu=\eta \Gamma\left(1+\frac{1}{\xi}\right) \\
& \sigma^{2}=\eta^{2}\left[\Gamma\left(1+\frac{2}{\xi}\right)-\Gamma^{2}\left(1+\frac{1}{\xi}\right)\right],
\end{aligned}
$$

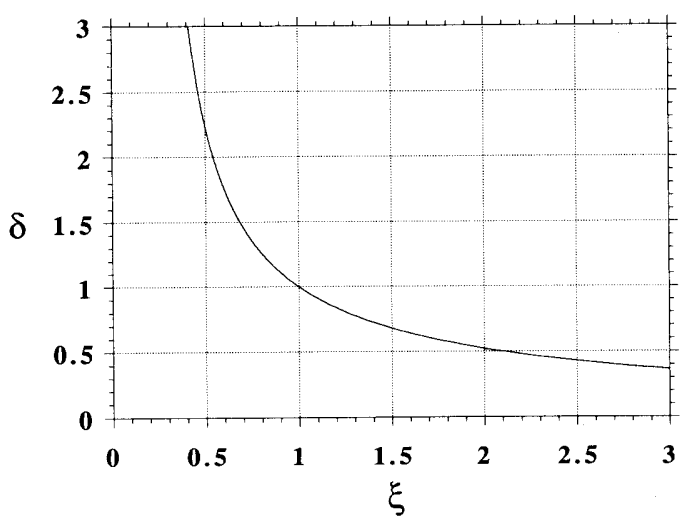

Fig. 2. Dependence of the coefficient of variation $(\delta=\sigma / \mu)$ on the shape parameter $(\xi)$ of the Weibull distribution (eq. (10)).

respectively. It follows from eqs. (8) and (9) that the coefficient of variation $\delta(=\sigma / \mu)$ of the wind speed is a function of $\xi$ only:

$\delta=\sqrt{\frac{\Gamma(1+2 / \xi)}{\Gamma^{2}(1+1 / \xi)}-1 .}$

The dependence of $\delta$ on $\xi$ is illustrated in Fig. 2 . A rough estimate of one of these quantities in terms of the other over the range of $\delta$ and $\xi$ likely to be encountered in the field is given by $\delta \xi \approx 1$.

\section{The mean transfer velocity and its dependence on the wind-speed probability structure}

Assuming the gas transfer velocity to be a monotonic increasing function of wind speed, the cumulative probability distribution of the transfer velocity $p(\beta>B)$ is equal to that of the wind speed $v_{\mathrm{B}}$ at which $\beta=B$, and so is given by $F\left(v_{\mathrm{B}}\right)$. The mean transfer velocity associated with this probability distribution is given by integrating the product of the transfer velocity $\beta(v)$ and the windspeed probability density $f(v)$ over the whole range of wind speeds:

$\bar{\beta}=\int_{0}^{\infty} f(v) \beta(v) \mathrm{d} v$.

If the wind speed follows a Weibull distribution, $f(v)$ is given by eq. (7). Assuming a trilinear (eq. 4) 
or power-law (eq. 5) function for $\beta(v)$ thus allows an analytical expression for the mean gas transfer velocity $\bar{\beta}$ to be obtained.

\subsection{The mean transfer velocity based on the tri- linear relationship}

Livingstone (1988) derived an expression for $\bar{\beta}$ based on the Weibull distribution and a bilinear dependence of $\beta$ on $v$. Extending his approach to the trilinear relationship (eq. (4)), $\bar{\beta}$ can be computed as the sum of three components, $\beta_{1}, \beta_{2}$ and $\beta_{3}$, associated with wind-speed regimes I, II and III respectively:

$$
\begin{aligned}
\beta_{1} & =\beta_{0} \int_{0}^{v_{\mathrm{a}}} f(v) \mathrm{d} v+q_{1} \int_{0}^{v_{\mathrm{a}}} f(v) v \mathrm{~d} v \\
& =\beta_{0}\left[1-F\left(v_{\mathrm{a}}\right)\right]+q_{1} v_{1}, \\
\beta_{2} & =\left[\beta_{0}-\left(q_{2}-q_{1}\right) v_{\mathrm{a}}\right] \int_{v_{\mathrm{a}}}^{v_{\mathrm{b}}} f(v) \mathrm{d} v \\
& +q_{2} \int_{v_{\mathrm{a}}}^{v_{\mathrm{b}}} f(v) v \mathrm{~d} v \\
& =\left[\beta_{0}-\left(q_{2}-q_{1}\right) v_{\mathrm{a}}\right]\left[F\left(v_{\mathrm{a}}\right)-F\left(v_{\mathrm{b}}\right)\right] \\
& +q_{2} v_{2}, \\
\beta_{3} & =\left[\beta_{0}-\left(q_{2}-q_{1}\right) v_{\mathrm{a}}-\left(q_{3}-q_{2}\right) v_{\mathrm{b}}\right] \\
& \times \int_{v_{\mathrm{b}}}^{\infty} f(v) \mathrm{d} v+q_{3} \int_{v_{\mathrm{b}}}^{\infty} f(v) v \mathrm{~d} v \\
& =\left[\beta_{0}-\left(q_{2}-q_{1}\right) v_{\mathrm{a}}-\left(q_{3}-q_{2}\right) v_{\mathrm{b}}\right] F\left(v_{\mathrm{b}}\right) \\
& +q_{3} v_{3} .
\end{aligned}
$$

\section{Hence:}

$$
\begin{aligned}
\bar{\beta} & =\beta_{1}+\beta_{2}+\beta_{3} \\
& =\beta_{0}+q_{1}\left[v_{1}+v_{\mathrm{a}} F\left(v_{\mathrm{a}}\right)\right] \\
& -q_{2}\left[v_{2}+v_{\mathrm{b}} F\left(v_{\mathrm{b}}\right)-v_{\mathrm{a}} F\left(v_{\mathrm{a}}\right)\right] \\
& +q_{3}\left[v_{3}-v_{\mathrm{b}} F\left(v_{\mathrm{b}}\right)\right] .
\end{aligned}
$$

The velocities $v_{1}, v_{2}$ and $v_{3}$ represent the contributions of wind-speed regimes I, II and III, respectively, to the mean wind speed. Making the simplifying substitutions $s=1+1 / \xi$ and $x=(v / \eta)^{\xi}$, these contributions are given by:

$$
\begin{aligned}
& v_{1}=\int_{0}^{v_{\mathrm{a}}} f(v) v \mathrm{~d} v=\eta \gamma\left(s, x_{\mathrm{a}}\right), \\
& v_{2}=\int_{v_{\mathrm{a}}}^{v_{\mathrm{b}}} f(v) v \mathrm{~d} v=\eta\left[\gamma\left(s, x_{\mathrm{b}}\right)-\gamma\left(s, x_{\mathrm{a}}\right)\right], \\
& v_{3}=\int_{v_{\mathrm{b}}}^{\infty} f(v) v \mathrm{~d} v=\eta\left[\Gamma(s)-\gamma\left(s, x_{\mathrm{b}}\right)\right],
\end{aligned}
$$

where $\gamma\left(s, x_{\mathrm{a}}\right)$ and $\gamma\left(s, x_{\mathrm{b}}\right)$ are the incomplete gamma functions $\int_{0}^{x_{\mathrm{a}}} x^{s-1} \mathrm{e}^{-x} \mathrm{~d} x$ and $\int_{0}^{x_{\mathrm{b}}} x^{s-1} \mathrm{e}^{-x} \mathrm{~d} x$, respectively, and $\Gamma(s)=\gamma(s, x \rightarrow \infty)$ is the complete gamma function, for which tabulated values are available (e.g., Abramowitz and Stegun, 1970). The mean wind speed $v_{1}+v_{2}+v_{3}$ over the complete velocity range is seen to be given by $\Gamma(s)$, agreeing with eq. (8). Evaluation of the incomplete gamma function $\gamma(s, x)$ can be achieved by converting it into Kummer's confluent hypergeometric function $M(1,1+s, x)$ as follows (Abramowitz and Stegun, 1970, §6.5.12):

$\gamma(s, x)=s^{-1} x^{s} \mathrm{e}^{-x} M(1,1+s, x)$,

and computing $M$ according to $\$ 13.1 .2$ of Abramowitz and Stegun (1970).

\subsection{The mean transfer velocity based on the power- law relationship}

Based on the power-law relationship (eq. (5)), the probability of the observed transfer velocity $\beta$ exceeding a given value $B$ is:

$p(\beta>B)=F\left(v_{\mathrm{B}}\right)=\exp -\left(\frac{B-\beta_{0}}{r \eta^{n}}\right)^{\xi / n}$,

where $v_{\mathrm{B}}$ is the wind speed at which $\beta=B$. Thus if the power-law relationship (eq. (5)) applies, and if the wind speed follows the two-parameter Weibull distribution (eq. (6)), the transfer velocity follows a three-parameter Weibull distribution with scale parameter $r \eta^{n}$, shape parameter $\xi / n$ and location parameter $\beta_{0}$. From eq. (8), the corresponding expression for the mean gas transfer velocity is thus:

$\bar{\beta}=\beta_{0}+r \int_{0}^{\infty} f(v) v^{n} \mathrm{~d} v=\beta_{0}+r \eta^{n} \Gamma\left(1+\frac{n}{\xi}\right)$.

For the specific case of a Rayleigh distribution (i.e., $\xi=2$ ) and a quadratic dependence of transfer velocity on wind speed $\left(\beta_{0}=0 ; n=2\right)$ as treated by Wanninkhof (1992), $\bar{\beta}$ is given by $r \eta^{2}$, where 
$\eta^{2}=4 \mu^{2} / \pi$ for $\xi=2$ (eq. (8)). From eq. (10), however, it can be seen that the Rayleigh distribution is not universally applicable, as its use implies that the standard deviation of the wind speed is approximately half the mean $(\delta=\sqrt{4 / \pi-1}$ from eq. (10)). In general, therefore, eq. (17) is to be preferred for power-law calculations.

\subsection{Dependence of the mean transfer velocity on the Weibull coefficients}

The dependence of the mean gas transfer velocity $\bar{\beta}$ on the scale parameter $\eta$ as derived from the trilinear (eq. (13)) and power-law (eq. (17)) relationships is illustrated in Fig. 3 for various values of $\xi$ typical of surface wind-speed distributions $(1.0 \leqslant \xi \leqslant 2.5)$. The form of the dependence of $\bar{\beta}$ on $\eta$ and $\xi$ predicted by eqs. (13) and (17) over
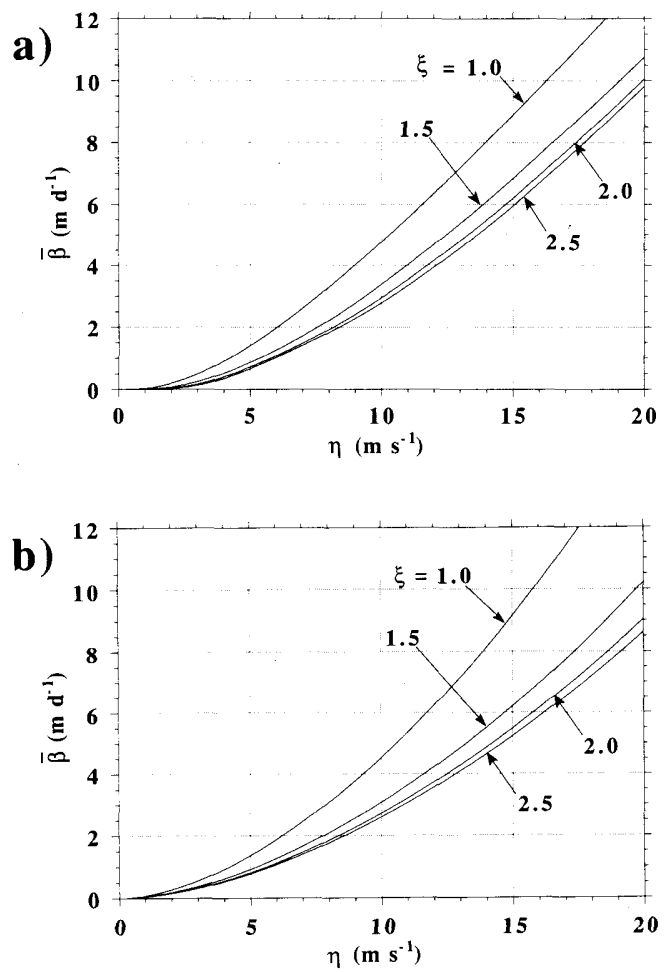

the range $0 \mathrm{~m} \mathrm{~s}^{-1} \leqslant \eta \leqslant 20 \mathrm{~m} \mathrm{~s}^{-1}$ is seen to be broadly similar, although absolute values of $\bar{\beta}$ do differ somewhat (Figs. 3a, b). Predictions of $\bar{\beta}$ at low values of $\eta$ (i.e., at low wind speeds) based on these two equations (Figs. 3c, d) tend to agree less than at higher values, as would be expected from the lack of agreement between the two underlying models evident in Fig. 1b. For $\xi>1, \bar{\beta}$ is seen to be fairly insensitive to $\xi$, implying that the shape of the wind-speed probability distribution is not critical for the determination of the mean transfer velocity, and that an approximate estimate of $\xi$ (accurate to, say, \pm 0.1 ) should therefore in most cases suffice to give a comparatively good estimate of $\bar{\beta}$. This is especially true for $\xi>1.5$, since sensitivity to $\xi$ decreases rapidly with increasing $\xi$. (As will be shown below, neglecting non-linear wind effects altogether is equivalent to setting $\xi \rightarrow \infty$.)
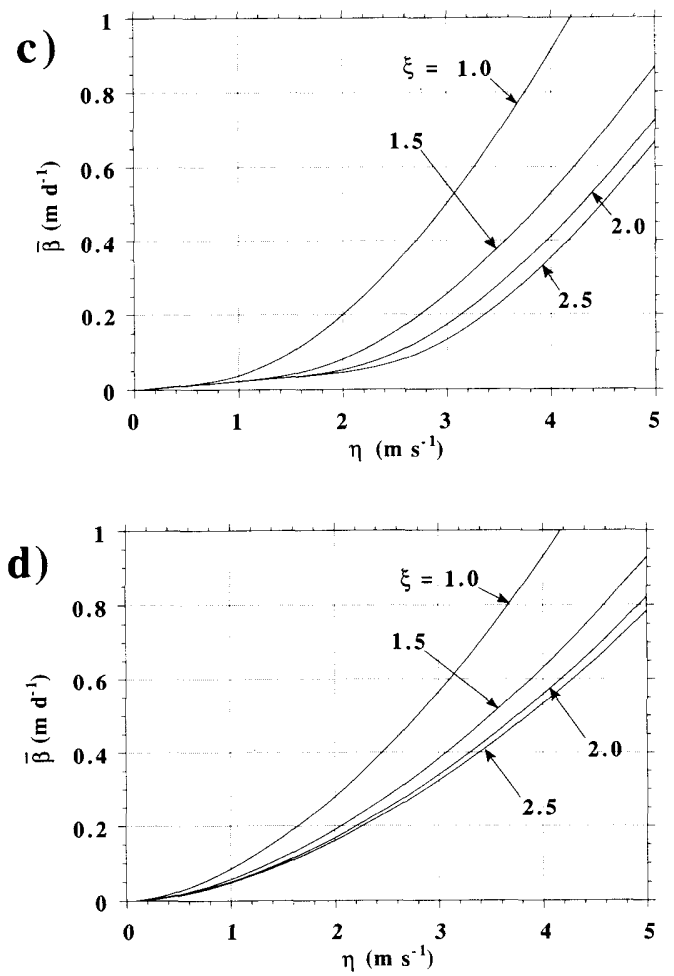

Fig. 3. Predicted dependence of the mean gas transfer velocity $\bar{\beta}$ (for $\mathrm{O}_{2}$ at $4^{\circ} \mathrm{C}$, i.e., $\mathrm{Sc}=1242$ ) on the scale parameter $\eta$ of the Weibull wind-speed distribution for a realistic range of values of the shape parameter $\xi$. Curves (a) and (c) illustrate eq. (13), based on the trilinear relationship of Liss and Merlivat (1986) (see Table 1 for coefficients); curves (b) and (d) illustrate eq. (17), based on the power-law relationship of Wanninkhof and Bliven (1991). The forms of the dependence are illustrated for $\eta$ ranging from $0-20 \mathrm{~m} \mathrm{~s}^{-1}(\mathrm{a}, \mathrm{b})$ and $0-5 \mathrm{~m} \mathrm{~s}^{-1}(\mathrm{c}, \mathrm{d})$. 
The transfer velocity $\bar{\beta}$ is generally much more sensitive to $\eta$ than to $\xi$ : the scaling of the windspeed probability distribution is thus seen to be of prime importance in predicting the mean transfer velocity, and the scale parameter $\eta$ must therefore be estimated as accurately as possible.

\subsection{Dependence of the mean transfer velocity on the mean and coefficient of variation of the wind speed}

The fact that the coefficient of variation $\delta$ $(=\sigma / \mu)$ of the wind speed is a function of $\xi$ only (eq. (10)) allows the representation of the relationships shown in Fig. 3 in a more intuitively meaningful fashion, viz. in terms of the dependence of the mean gas transfer velocity on mean wind speed (eq. (8)) for various values of the coefficient of variation (Fig. 4). If the wind speed $v$ is constant over a given time period, it follows that $\sigma^{2}=0$, $\delta=0, \xi \rightarrow \infty$ and $v=\mu$. Thus the dependence of $\bar{\beta}$ on $\mu$ for the case $\delta=0$ as shown in Fig. 4 is identical to that of $\beta$ on $v$ in Fig. 1. Due to the nonlinearity of the wind-speed dependence, however, an increase in the coefficient of variation at any given mean wind speed will cause an increase in the mean gas transfer velocity. The resulting relationships between $\bar{\beta}$ and $\mu$ are illustrated in Fig. 4 for $\delta$ varying from 0 to 1 in steps of 0.2 , corresponding to $\xi \rightarrow \infty$ and $\xi=5.8,2.7,1.7,1.3$ and 1.0 , respectively. Values of $\delta$ exceeding unity (i.e., values of $\xi<1$ ) are unlikely to occur in wind-speed data, and so mean gas transfer velocities (for $\mathrm{Sc}=1242$ ) are predicted to lie between the curves
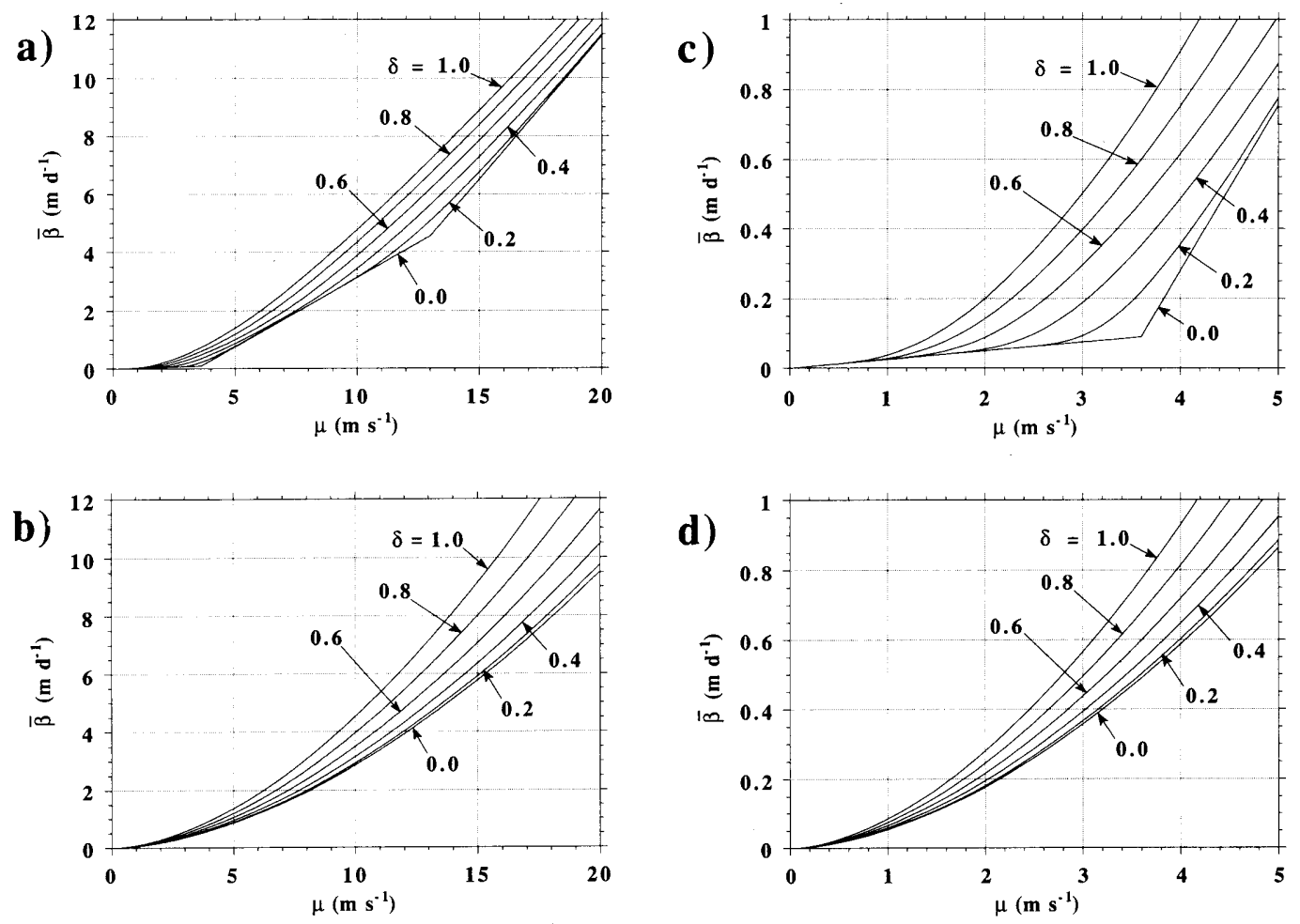

Fig. 4. Predicted dependence of the mean gas transfer velocity $\bar{\beta}$ (for $\mathrm{O}_{2}$ at $4{ }^{\circ} \mathrm{C}$, i.e., $\mathrm{Sc}=1242$ ) on the mean wind speed $\mu$ for a realistic range of values of the coefficient of variation $\delta(=\sigma / \mu=0,0.2,0.4,0.6,0.8,1.0$, corresponding to $\xi \rightarrow \infty$ and $\xi=5.8,2.7,1.7,1.3$ and 1.0 , respectively), assuming a Weibull wind-speed distribution. Curves (a) and (c) are derived from eq. (13), based on the trilinear relationship of Liss and Merlivat (1986) (see Table 1 for coefficients); curves (b) and (d) are derived from eq. (17), based on the power-law relationship of Wanninkhof and Bliven (1991). The forms of the dependence are illustrated for $\mu$ ranging from $0-20 \mathrm{~m} \mathrm{~s}^{-1}(\mathrm{a}, \mathrm{b})$ and $0-5 \mathrm{~m} \mathrm{~s}^{-1}(\mathrm{c}, \mathrm{d})$. 
of Fig. 4 corresponding to $\delta=0$ and $\delta=1$. Thus $\bar{\beta}$ is predicted to lie within the following ranges:

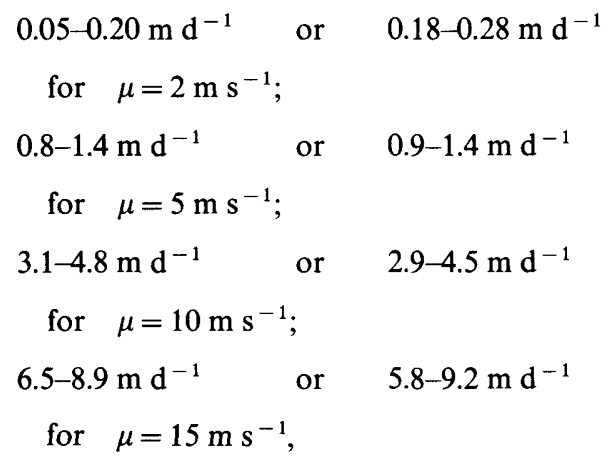

where the first of each pair of ranges refers to predictions based on the L-M relationship (Figs. $4 \mathrm{a}, \mathrm{c})$ and the second to predictions based on the W-B relationship (Figs. 4b, d). The lower of the two values defining each range is the value yielded by the unmodified L-M or W-B relationship, and the higher gives the maximum value likely to be attained as a result of the non-linear wind effect. Estimates of the non-linear wind effect at wind speeds exceeding $5 \mathrm{~m} \mathrm{~s}^{-1}$ are probably realistic (at least for shallow water bodies), since both L-M and $\mathbf{W}-\mathbf{B}$ relationships agree well with the large amount of data available at intermediate and high wind speeds (regimes II and III). At lower wind speeds, however, the relative importance of the non-linear wind effect is likely to be exaggerated, since neither the $\mathrm{L}-\mathrm{M}$ nor the $\mathrm{W}-\mathrm{B}$ relationships take account of possible wind-independent gas exchange at low wind speeds as outlined in Subsection 2.2 above.

It is immediately obvious from the form of the curves in Figs. $4 \mathrm{a}$ and $4 \mathrm{c}$ that, even although the instantaneous gas transfer velocity may exhibit a trilinear dependence on instantaneous wind speed, the mean gas transfer velocity cannot exhibit such a dependence on the mean wind speed. The nonlinear wind effect causes the smoothing out of the characteristic trilinear form of the curve, giving it the superficial appearance of a power-law curve. Since gas exchange in natural water bodies depends not only on the instantaneous wind speed, but also on turbulence generated by previous wind events, it is likely that the instantaneous gas transfer velocity depends not only on the instantaneous wind speed, but also partly on the mean wind speed over a certain period of past time. This implies that the best description of the actual situation existing in natural water bodies will probably not be given by a curve such as the trilinear curve with abrupt gradient changes at specific critical wind speeds marking transitions between the qualitative processes involved (although such a curve is useful from the point of view of understanding the physical processes themselves), but rather by a smooth curve with no such abrupt changes.

The magnitude of the maximum likely nonlinear wind-speed effect is easily calculated in the case of the general power-law relationship (eq. (5)) by subtracting the value of $\bar{\beta}$ at $\xi \rightarrow \infty$ from that at $\xi=1$ in eq. (17), yielding $r \mu^{n}[\Gamma(1+n)-1]$. Thus the maximum fractional increase which the gas transfer velocity is likely to undergo as a result of the non-linear wind-speed effect, $\Gamma(1+n)-1$, is independent of the mean wind speed, being a function of the exponent $\mathbf{n}$ alone. For the value $n=1.73$ given by Wanninkhof and Bliven (1991), this fraction is $58 \%$. In general, $\mathrm{n}$ is likely to lie between 1.5 (Hartmann and Hammond, 1984) and 2.0 (Kanwisher, 1963), corresponding to values of $32 \%$ and $100 \%$, respectively, for $\Gamma(1+n)-1$. This gives a rough estimate of the magnitude of the error involved in ignoring the non-linear wind effect in wind-speed regimes II and III, where it is justifiable to neglect the wind-independent contribution to gas exchange. This error is unlikely to exceed $100 \%$.

\section{Example of application to lake oxygenation}

Computation of a mean transfer velocity in terms of parameters of the wind-speed distribution would be of practical use in the computation of long-term mean gas exchange rates across atmosphere-ocean or atmosphere-lake interfaces. The example chosen here is that of lake oxygenation, where a simple exponential model with a constant transfer velocity is often employed to estimate the rise in lake $\mathrm{O}_{2}$ content occurring during winter. In this model, similar to eq. (2), the $\mathrm{O}_{2}$ flux $F_{\mathrm{O}_{2}}(t)$ across the air-water interface is given by the product of a constant (mean) transfer velocity $\bar{\beta}$ and a smoothed $\mathrm{O}_{2}$ saturation deficit $C_{\mathrm{s}}-C(t)$ across the air-water interface (where $C_{\mathrm{s}}$ represents the $\mathrm{O}_{2}$ saturation concentration and $C(t)$ the mean 
$\mathrm{O}_{2}$ concentration in a homogeneous, well-mixed lake with mean depth $\bar{z}$ ):

$F_{\mathrm{O}_{2}}(t)=\bar{\beta}\left[C_{\mathrm{s}}-C(t)\right]$.

During lake oxygenation, the mean $\mathrm{O}_{2}$ concentration $C(t)$ increases with time $t$ from an initial value $C_{0}$, approaching an equilibrium concentration $C_{\infty}$ exponentially as follows:

$C(t)=C_{\infty}-\left(C_{\infty}-C_{0}\right) \mathrm{e}^{-k t}$,

where

$C_{\infty}=C_{\mathrm{s}}-J / k$,

$k=\bar{\beta} / \bar{z}$ is the exchange coefficient, and $J$ is the mean net $\mathrm{O}_{2}$ consumption rate per unit lake volume and time. Applying this one-box model during lake turnover, estimates for the $\mathrm{O}_{2}$ exchange coefficient $k$ (and hence for the transfer velocity $\bar{\beta}$ ) for any pair of $\mathrm{O}_{2}$ measurements can be obtained by solving eqs. (19) and (20) for the two unknowns $C_{\infty}$ and $k$, if $C_{s}$ and $J$ are known or can be estimated independently.

The water body chosen for this study, Aegerisee, is a $U$-shaped glacially-formed lake situated at $724 \mathrm{~m}$ a.s.l. in the northern foothills of the Swiss Alps. It has a maximum depth of $83 \mathrm{~m}$, a surface area of $7.275 \mathrm{~km}^{2}$, a volume of $356 \times 10^{6} \mathrm{~m}^{3}$ and is meso/eutrophic. $\mathrm{O}_{2}$ and temperature conditions over a period of years are well documented (Livingstone, 1988; Livingstone and Imboden, 1989).

The main lake inflows are generally saturated with $\mathrm{O}_{2}$ in winter (e.g., $12.9 \mathrm{~g} \mathrm{O}_{2} \mathrm{~m}^{-3}$ in January on average) (Livingstone, 1991), whilst the mean lake $\mathrm{O}_{2}$ concentration increases from about $8 \mathrm{~g}$ $\mathrm{O}_{2} \mathrm{~m}^{-3}$ to $11 \mathrm{~g} \mathrm{O}_{2} \mathrm{~m}^{-3}$ during the course of a winter (Fig. 5). The mean lake throughflow, however, is about $1.7 \mathrm{~m}^{3} \mathrm{~s}^{-1}$ (i.e., about $1.3 \%$ of the total lake volume per month) during the winter months, so that the direct influence of the throughflow on the winter $\mathrm{O}_{2}$ regime can be neglected. Winter productivity was estimated to be about $40 \mathrm{mg} \mathrm{C} \mathrm{m}^{-2} \mathrm{~d}^{-1}\left({ }^{14} \mathrm{C}\right.$ method), which corresponds to a $\mathrm{O}_{2}$ production rate per unit total lake volume of less than $0.1 \mathrm{~g} \mathrm{O}_{2} \mathrm{~m}^{-3}$ month ${ }^{-1}$. Thus the only significant source of $\mathrm{O}_{2}$ to the lake in winter is exchange with the atmosphere through the lake surface.

The gross $\mathrm{O}_{2}$ consumption rate during turnover was estimated as the hypolimnetic $\mathrm{O}_{2}$ consumption rate occurring during the previous summer, calculated according to Lasenby (1975). After correcting to the volume of the whole lake, taking separate account of the contributions of the area sink (sediment consumption) and volume sink (consumption in the water column) (Bossard and Gächter, 1981), a value for the gross $\mathrm{O}_{2}$ consumption rate was obtained for each of the 6 years. Corresponding net $\mathrm{O}_{2}$ consumption rates $J$ obtained by correcting the gross consumption rates for productivity are listed in Table 2 .

Pairs of completely homogeneous $\mathrm{O}_{2}$ profiles from Aegerisee were available which had been obtained during turnover in each of the 6 winters $1950 / 51,1974 / 75,1975 / 76,1978 / 79,1981 / 82$ and $1983 / 84$. Turnover temperatures varied from $3.3^{\circ} \mathrm{C}$ to $5.0^{\circ} \mathrm{C}$, corresponding to saturation concentrations $C_{\mathrm{s}}$ of $12.0 \pm 0.3 \mathrm{~g} \mathrm{O}_{2} \mathrm{~m}^{-3}$ at the mean winter

Table 2. Net consumption rate $(J)$, equilibrium concentration $\left(C_{\infty}\right)$, exchange coefficient $(k)$, gas transfer velocity $(\bar{\beta})$ and film thickness $(\delta z)$ for $\mathrm{O}_{2}$ during turnover in Aegerisee

\begin{tabular}{cccccc}
\hline Winter & $\begin{array}{c}J \\
\left(\mathrm{~g} \mathrm{O}_{2} \mathrm{~m}^{-3} \mathrm{yr}^{-1}\right)\end{array}$ & $\begin{array}{c}C_{\infty} \\
\left(\mathrm{g} \mathrm{O}_{2} \mathrm{~m}^{-3}\right)\end{array}$ & $\begin{array}{c}k \\
\left(\mathrm{yr}^{-1}\right)\end{array}$ & $\begin{array}{c}\bar{\beta} \\
\left(\mathrm{m} \mathrm{d}^{-1}\right)\end{array}$ & $\begin{array}{c}\delta z \\
(\mu \mathrm{m})\end{array}$ \\
\hline $1950 / 51$ & 2.8 & 11.6 & 6.5 & 0.87 & 132 \\
$1974 / 75$ & 5.6 & 11.1 & 6.0 & 0.80 & 136 \\
$1975 / 76$ & 4.5 & 11.1 & 5.1 & 0.69 & 159 \\
$1978 / 79$ & 5.8 & 10.9 & 5.0 & 0.67 & 162 \\
$1981 / 82$ & 5.8 & 11.2 & 7.2 & 0.96 & 113 \\
$1983 / 84$ & 5.8 & 11.2 & 7.4 & 1.00 & 109 \\
\hline mean & 5.1 & 11.2 & 6.2 & 0.83 & 135 \\
S.D. & 1.2 & 0.2 & 1.0 & 0.14 & 22 \\
\hline
\end{tabular}



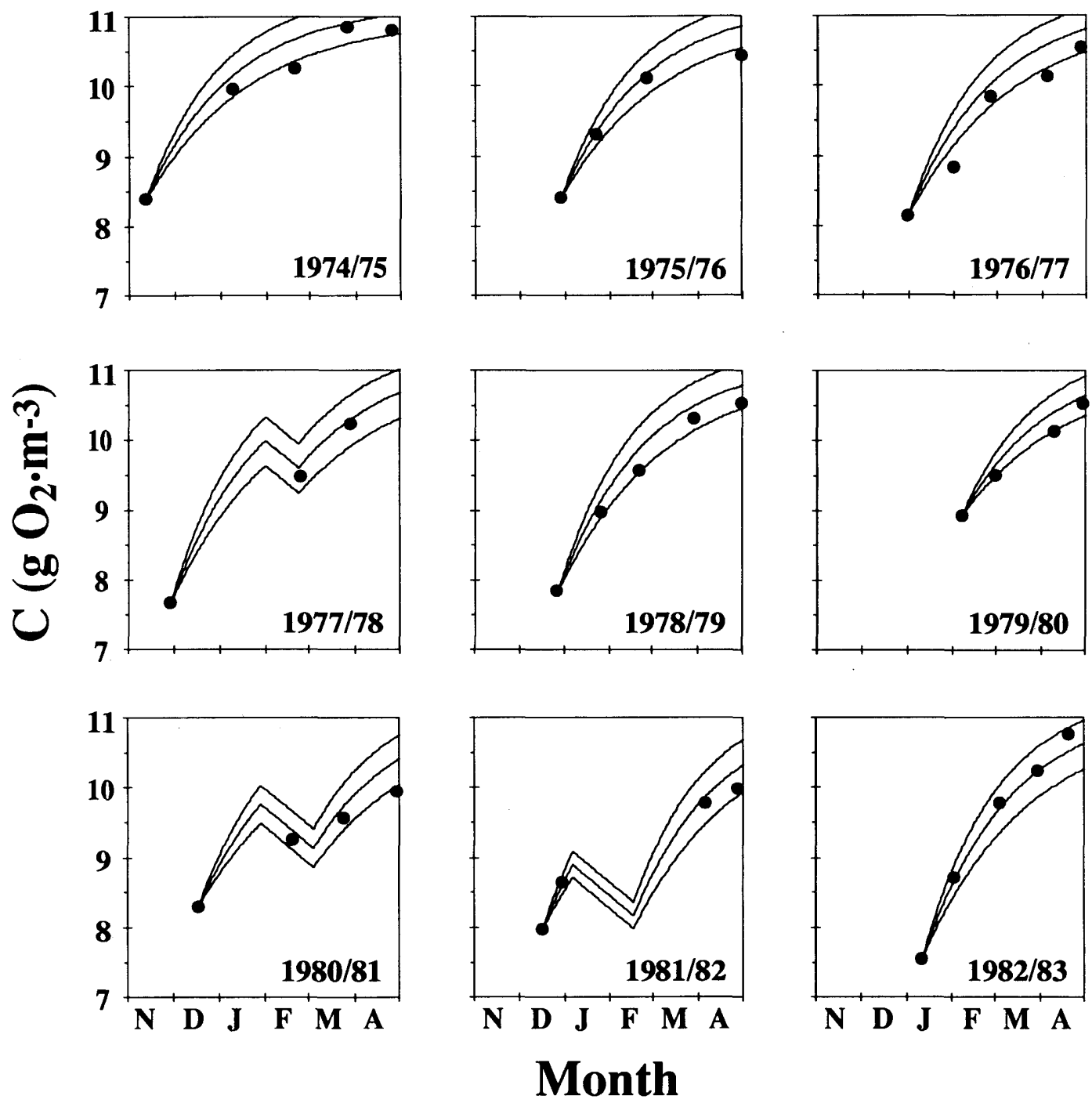

Fig. 5. Application of the one-box exponential model with constant coefficients (eqs. 18-20) to the mean $\mathrm{O}_{2}$ concentration in Aegerisee from November to April for the period 1974/75 to 1982/83. Solid circles represent measured data. For each winter, the middle curve represents the exponential increase in $\mathrm{O}_{2}$ concentration predicted from eqs. (19) and (20) using mean values of $C_{\infty}$ and $\bar{\beta}$ from Table 1; upper and lower curves represent the $\mathrm{O}_{2}$ concentration predicted by increasing and decreasing both $C_{\infty}$ and $\bar{\beta}$ by one standard deviation $\left(C_{\infty}=11.2 \pm 0.2 \mathrm{~g} \mathrm{O}_{2} \mathrm{~m}^{-3} \mathrm{yr}^{-1}\right.$; $\left.\bar{\beta}=0.83 \pm 0.15 \mathrm{~m} \mathrm{~d}^{-1}\right)$. During periods of ice cover $(1977 / 78 ; 1980 / 81 ; 1981 / 82), \bar{\beta}$ was set to zero.

air pressure $(932 \mathrm{hPa})$ prevailing at the lake surface. For each pair of $\mathrm{O}_{2}$ profiles, eqs. (19) and (20) were solved for $C_{\infty}$ and $k$ using the already determined values of $J$. The resulting estimates of $C_{\infty}, k$ and $\bar{\beta}$ are listed in Table 2. Equivalent film thicknesses calculated using the two-film model of Whitman (1923) and Lewis and Whitman (1924) are also listed in order to facilitate comparison of the Aegerisee results with the results of other lake gas exchange studies commonly presented in this form (e.g., Emerson, 1975). Variations in the equilibrium concentration $C_{\infty}$ are seen to be slight (mean $=11.2 \mathrm{~g} \mathrm{O}_{2} \mathrm{~m}^{-3}$; st. $\mathrm{dev}$. $=$ $0.2 \mathrm{~g} \mathrm{O}_{2} \mathrm{~m}^{-3}$ ), whereas the $\mathrm{O}_{2}$ transfer velocity $\bar{\beta}$ 
varies more strongly (mean $=0.83 \mathrm{~m} \mathrm{~d}^{-1}$; st. dev. $=0.14 \mathrm{~m} \mathrm{~d}^{-1}$ ). In spite of this variation, it was found that the exponential increase in the mean $\mathrm{O}_{2}$ concentration in Aegerisee in all 9 winters from $1974 / 75$ to $1982 / 83$ can be modelled surprisingly well using the constant values $C_{\infty}=11.2 \mathrm{~g} \mathrm{O}_{2} \mathrm{~m}^{-3}$ and $\bar{\beta}=0.83 \mathrm{~m} \mathrm{~d}^{-1}$ (i.e., $k=6.2 \mathrm{yr}^{-1}$ ) in eqs. (19) and (20), with $\bar{\beta}$ set to zero during periods of ice cover (Fig. 5).

The range of oxygen transfer velocities in winter found in Aegerisee ( 0.7 to $1.0 \mathrm{~m} \mathrm{~d}^{-1}$, corresponding to stagnant film thicknesses of $110-160 \mu \mathrm{m}$ ) is similar to values found in other subalpine Swiss lakes of similar size subject to the same large-scale and mesoscale meteorological events. According to Imboden et al. (1983), for instance, $\mathrm{O}_{2}$ transfer velocities in Baldeggersee range from 0.7 to $1.0 \mathrm{~m} \mathrm{~d}^{-1}$. Winter gas transfer velocities measured by Jähne et al. (1984b) in Baldeggersee and in Sempachersee correspond to $\mathrm{O}_{2}$ transfer velocities at $4^{\circ} \mathrm{C}$ ranging from $0.6-0.8 \mathrm{~m} \mathrm{~d}^{-1}$ and from $0.8-1.0 \mathrm{~m} \mathrm{~d}^{-1}$, respectively. Thus a value of about $0.8 \mathrm{~m} \mathrm{~d}^{-1}$ may be fairly representative of winter $\mathrm{O}_{2}$ transfer velocities in medium-sized central European subalpine lakes.

The constancy of $\bar{\beta}$ between years and between neighbouring lakes of similar size implies a corresponding between-year constancy of the factors upon which the mean gas exchange rate depends. Table 3 shows this to be the case for the mean winter wind speed measured at meteorological stations immediately adjacent to seven Swiss lakes: between-year variability (measured as the coefficient of variation ) is approximately $\pm 10 \%$ for all cases listed. Mean wind speeds between $1.6 \mathrm{~m} \mathrm{~s}^{-1}$ and $2.8 \mathrm{~m} \mathrm{~s}^{-1}$ appear to be typical for Swiss lakes. However, applying the $\mathrm{L}-\mathrm{M}$ and $\mathrm{W}-\mathrm{B}$ relationships illustrated in Fig. 1 directly to the mean values of the transfer velocity and wind speed, a mean $\mathrm{O}_{2}$ transfer velocity of the magnitude found in Aegerisee would imply a mean wind speed of about $5 \mathrm{~m} \mathrm{~s}^{-1}$. Unfortunately there is no meteorological station at the Aegerisee lakeside; however, wind measurements conducted at the lake shore during the period 30 January to 20 April 1982 (Table 4) yielded a mean wind speed of only $1.76 \mathrm{~m} \mathrm{~s}^{-1}$ at $10 \mathrm{~m}$ above the lake surface (1925 hourly measurements). During the same period, the mean wind speed measured at the Zugerberg meteorological station, situated $6 \mathrm{~km}$ from the lake and $251 \mathrm{~m}$ above the lake surface, was $2.31 \mathrm{~m} \mathrm{~s}^{-1}$. This compares with a mean winter wind speed of $2.41 \mathrm{~m} \mathrm{~s}^{-1}$ at the same station (based on 4350 measurements from November to April, 1972-1979). The period 30 January to 20 April 1982 can thus be considered representative

Table 3. Mean winter wind speeds ( $\bar{v} ;$ November to April) measured at 7 Swiss lakeshore stations, with the between-year standard deviation of the mean $\left(\sigma_{v}\right)$ and corresponding coefficient of variation $\left(\delta_{v}=\sigma_{v} / \bar{v}\right)$

\begin{tabular}{llccc}
\multicolumn{1}{c}{$\begin{array}{c}\text { Station } \\
\text { Period }\end{array}$} & \multicolumn{1}{c}{ Lake } & $\begin{array}{c}\bar{v} \\
\left(\mathrm{~m} \mathrm{~s}^{-1}\right)\end{array}$ & $\begin{array}{c}\sigma_{\mathrm{v}} \\
\left(\mathrm{m} \mathrm{s}^{-1}\right)\end{array}$ & $\delta_{\mathrm{v}}$ \\
\hline $\begin{array}{l}\text { Lugano } \\
\text { 1978/79-1985/86 }\end{array}$ & Lago di Lugano & 1.63 & 0.14 & 0.08 \\
$\begin{array}{l}\text { Interlaken } \\
\text { 1978/79-1985/86 }\end{array}$ & Brienzersee, Thunersee & 1.65 & 0.16 & 0.10 \\
$\begin{array}{l}\text { Pully } \\
\text { 1978/79-1990/91 }\end{array}$ & Lac Léman (Lake Geneva) & 1.75 & 0.19 & 0.11 \\
$\begin{array}{l}\text { Locarno-Magadino } \\
\text { 1978/79-1985/86 }\end{array}$ & Lago Maggiore & & & \\
$\begin{array}{l}\text { Zürich } \\
\text { 1971/72-1990/91 }\end{array}$ & Zürichsee & 1.86 & 0.18 & 0.10 \\
$\begin{array}{l}\text { Neuchâtel } \\
\text { 1978/79-1990/91 }\end{array}$ & Lac de Neuchâtel & 2.26 & 0.17 & 0.08 \\
$\begin{array}{l}\text { Altdorf } \\
1978 / 79-1985 / 86\end{array}$ & Urnersee & 2.60 & 0.25 & 0.09 \\
\hline
\end{tabular}


Table 4. Weibull shape parameter ( $\xi)$, Weibull scale parameter $(\eta)$ and mean speed $(\bar{v})$ of winter winds measured at the Aegerisee lake shore $10 \mathrm{~m}$ above the lake surface (AEG, period 30 January20 April 1982, 1925 measurements) and Zugerberg (ZBG1, period 30 January-20 April 1982, 240 measurements; ZBG2, November to April, 1971/72 to $1978 / 79,4350$ measurements)

\begin{tabular}{lcccc}
\hline & $\xi \pm$ C.I. & $\begin{array}{c}\eta \pm \text { C.I. } \\
\left(\mathrm{m} \mathrm{s}^{-1}\right)\end{array}$ & $\begin{array}{c}\mu \\
\left(\mathrm{m} \mathrm{s}^{-1}\right)\end{array}$ & $\begin{array}{c}\bar{v} \\
\left(\mathrm{~m} \mathrm{~s}^{-1}\right)\end{array}$ \\
\hline AEG & $1.01 \pm 0.04$ & $1.61 \pm 0.16$ & 1.60 & 1.76 \\
ZBG1 & $0.98 \pm 0.05$ & $2.45 \pm 0.51$ & 2.47 & 2.31 \\
ZBG2 & $1.04 \pm 0.02$ & $2.57 \pm 0.18$ & 2.53 & 2.41 \\
\hline
\end{tabular}

Weibull parameters and their $95 \%$ confidence intervals (C.I.) computed using Weibull's (1951) linearization and regression method (regression significant at $1 \%$ level, more than $98 \%$ of variance explained). Mean wind speed $\mu$ computed from the Weibull parameters using eq. (8); $\bar{v}$ computed directly from the wind-speed data.

of normal winter wind conditions, implying that the mean winter wind speed $10 \mathrm{~m}$ above the surface of Aegerisee is approximately $1.8 \mathrm{~m} \mathrm{~s}^{-1}$. Based on this value, which lies within the range of values found for other Swiss lakes listed in Table 3, it is obvious that neither the $\mathrm{L}-\mathrm{M}$ nor $\mathrm{W}-\mathrm{B}$ relationship can be applied directly to the mean wind speed in order to calculate a mean transfer velocity, as both grossly underestimate the actual value found. The calculated values of the transfer velocity at $v=1.8 \mathrm{~m} \mathrm{~s}^{-1}$ (Fig. 1b) are $0.05 \mathrm{~m} \mathrm{~d}^{-1}$ (L-M) and $0.15 \mathrm{~m} \mathrm{~d}^{-1}(\mathrm{~W}-\mathrm{B})$, or $6 \%$ and $18 \%$, respectively, of $0.83 \mathrm{~m} \mathrm{~d}^{-1}$.

Because of the non-linear form of the dependence of $\beta$ on $v$, actual values of the mean $\mathrm{O}_{2}$ transfer velocity in Aegerisee will exceed those obtained by applying the unmodified L-M and W-B relationships of Fig. 1 to the mean wind speed, but parameterization of the wind speed in terms of the Weibull distribution allows this effect to be taken into account. The commonly used (e.g., Justus et al., 1976, 1978) linearization method of Weibull (1951) was used to determine the Weibull parameters of the Aegerisee and Zugerberg windspeed data sets (Table 4). The parameters of the Zugerberg wind-speed distribution for the period 30 January to 20 April 1982 can be seen to agree closely with those for all winter winds (November to April) from 1972 to 1979 . Thus not only the mean wind speed, but also the probability structure of the scalar wind field over the lake as measured from 30 January to 20 April 1982 can be considered representative of normal winter conditions. As can be seen in Fig. 6, this probability structure is well represented by a Weibull distribution with the parameters $\xi=1.01$ and $\eta=$ $1.61 \mathrm{~m} \mathrm{~s}^{-1}$ from Table 4. In the particular case considered here, the shape parameter $\xi$ happens to be approximately unity, allowing considerable simplification of the relevant equations; this will, however, not normally be the case.

From Figs. 3 and 4 it is immediately apparent that the non-linear wind effect does not suffice to explain the high value of $\bar{\beta}$ observed. Computation of the mean $\mathrm{O}_{2}$ transfer velocity $\bar{\beta}$ based on the L-M relationship (eq. (13)) yields a value of $0.12 \mathrm{~m} \mathrm{~d}^{-1}$, with the components $\beta_{1}=0.03 \mathrm{~m} \mathrm{~d}^{-1}$, $\beta_{2}=0.09 \mathrm{~m} \mathrm{~d}^{-1}$ and $\beta_{3}=0.002 \mathrm{~m} \mathrm{~d}^{-1}$ (as expected, the contribution of $\beta_{3}$ to the mean value can be neglected due to the extremely low probability of the wind speed exceeding the critical velocity $v_{\mathrm{b}}$ ). The value $\bar{\beta}=0.12 \mathrm{~m} \mathrm{~d}^{-1}$, although significantly higher than that computed on the basis of the mean wind speed alone, thus still underestimates the actual mean value by a factor of seven. The value $\vec{\beta}=0.19 \mathrm{~m} \mathrm{~d}^{-1}$ obtained from the $\mathrm{W}-\mathrm{B}$ relationship (eq. (17)) underestimates the measured value by a factor of four. Thus it can be concluded from this example that, even when the effect of non-linearity is taken into account, neither the $\mathrm{L}-\mathrm{M}$ nor the $\mathrm{W}-\mathrm{B}$ relationship is likely to yield a useable value for the mean $\mathrm{O}_{2}$ transfer velocity: at most, an increase to about $0.25 \mathrm{~m} \mathrm{~d}^{-1}$ could possibly be accounted for in this way (Fig. 4d with $\mu=1.8 \mathrm{~m} \mathrm{~s}^{-1}$ and $\delta=1.0$ ). Further support for this conclusion is given by computing the cumulative probability distribution of the $\mathrm{O}_{2}$ transfer velocity $p(\beta>B)$. According to both $\mathrm{L}-\mathrm{M}$ and $\mathrm{W}-\mathrm{B}$, the $\mathrm{O}_{2}$ transfer velocity lies below the measured mean value of $0.83 \mathrm{~m} \mathrm{~d}^{-1}$ during about $96 \%$ of the time.

Based on the distribution illustrated in Fig. 6, Aegerisee wind speeds in winter can be estimated to lie below the critical value $v_{\mathrm{a}}=3.6 \mathrm{~m} \mathrm{~s}^{-1}$ during $89.5 \%$ of the time, and below $v_{\mathrm{b}}=13 \mathrm{~m} \mathrm{~s}^{-1}$ during $99.97 \%$ of the time. During most of the winter, the direct influence of the wind on gas exchange in the case of Aegerisee, and presumably in the case of other Swiss lakes with similar wind-speed distributions, can therefore be expected to be very limited. 

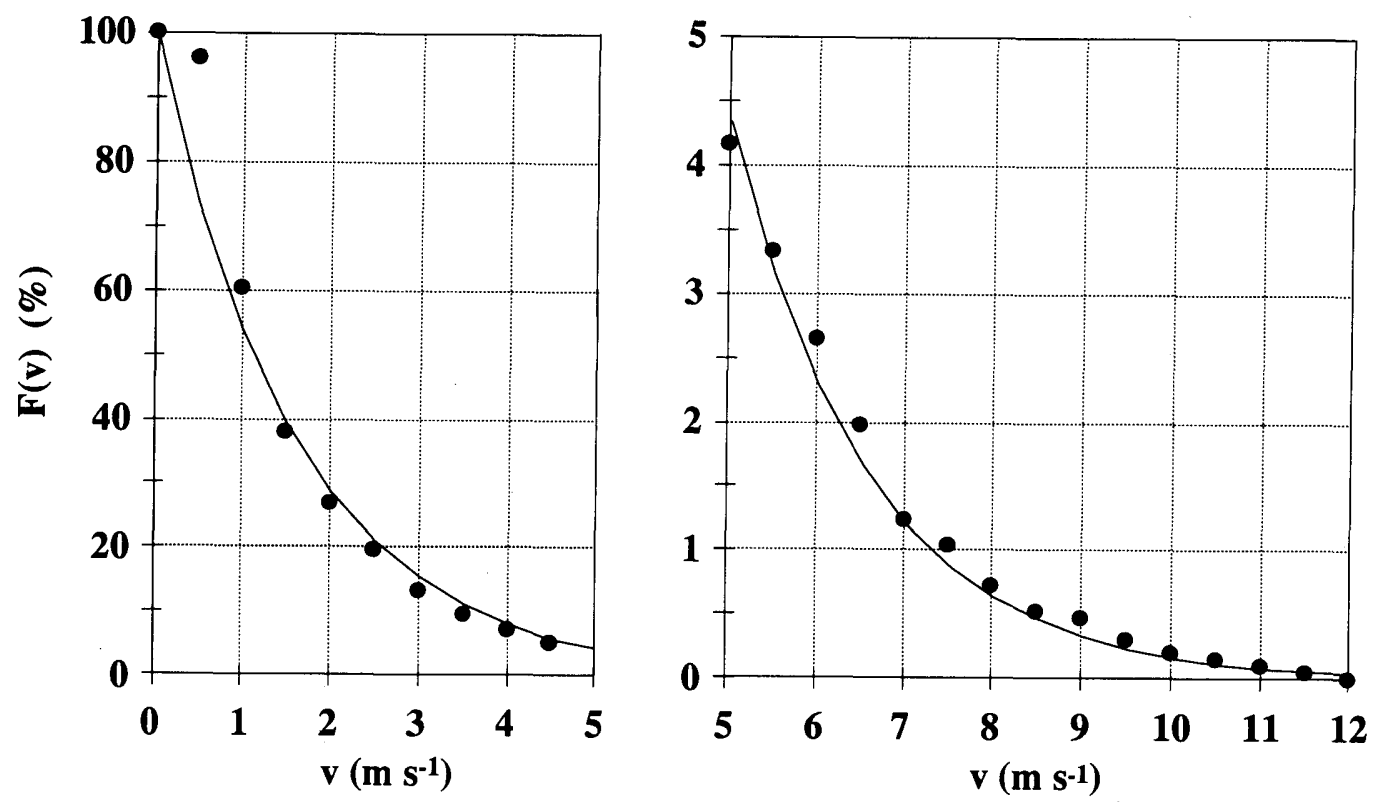

Fig. 6. Cumulative probability distribution of wind speed at a height of $10 \mathrm{~m}$ above the surface of Aegerisee (measured at the lake shore from 30 January to 20 April 1982; solid circles) fitted with a Weibull distribution (eq. (6) with Weibull parameters $\xi=1.01$ and $\eta=1.61$ from Table 3; curve). $F(v)$ is the probability of the measured wind speed exceeding a given value $v$.

The occurrence of extreme storm events has been shown to have a considerable effect on lake mixing (Imboden et al., 1988), and must also result in a corresponding enhancement of gas exchange. However, although exceptionally high rates of gas exchange may occasionally occur as a result of such storms, the extreme rarity of such events precludes the likelihood of their making a significant contribution to the mean gas transfer velocity.

In Section 2 above, it was mentioned that $\beta_{0}$ may be non-zero, and that $\beta$ may remain approximately constant at this value up to the critical wind speed $v_{\mathrm{a}}$. Assuming $\beta_{0}=0.35 \mathrm{~m} \mathrm{~d}^{-1}$ (from Liss et al., 1981: see Fig. $1 \mathrm{~b}$ ) and $q_{1}=0$, the trilinear relationship yields values of $v_{\mathrm{a}}=$ $4.1 \mathrm{~m} \mathrm{~s}^{-1}$ and $\bar{\beta}=0.41 \mathrm{~m} \mathrm{~d}^{-1}$. In order to obtain the value $\bar{\beta}=0.83 \mathrm{~m} \mathrm{~d}^{-1}$ from this relationship, values of $\beta_{0}=0.80 \mathrm{~m} \mathrm{~d}^{-1}$ and $v_{\mathrm{a}}=5.1 \mathrm{~m} \mathrm{~s}^{-1}$ would have to be assumed. This is practically equivalent to assuming the transfer velocity to be independent of the instantaneous wind speed. Applying the power-law relationship with $\beta_{0}=$ $0.35 \mathrm{~m} \mathrm{~d}^{-1}$ also yields an underestimate of the transfer velocity $\left(\bar{\beta}=0.53 \mathrm{~m} \mathrm{~d}^{-1}\right)$, although the result in this case is slightly more satisfactory. A value of $\beta_{0}=0.64 \mathrm{~m} \mathrm{~d}^{-1}$ would be necessary for the power-law relationship to yield $\bar{\beta}=0.83 \mathrm{~m} \mathrm{~d}^{-1}$.

There are many possible reasons for the poor agreement between the predicted course of lake oxygenation calculated on the basis of the two commonly used transfer velocity models employed here and the measured $\mathrm{O}_{2}$ data from Aegerisee. Wind action is not the only source of turbulent kinetic energy (TKE) to a lake: alterations in the stability of the water column brought about by heat gain and loss through the lake surface lead to changes in the TKE of the lake, promoting or inhibiting vertical mixing. The kinetic energy content of inflowing water also contributes to the available TKE. In addition, the TKE resulting from a wind event does not dissipate immediately the event is over, but remains in the lake for a period of time in the form of internal waves and seiches. A lake is therefore in a dynamic state even when the wind speed is zero. Thus, although the gas transfer velocity may be non-zero when the 
instantaneous wind speed is zero or very low, it does not necessarily follow that such a non-zero transfer velocity is completely wind-independent.

\section{Conclusions}

Wind speed is generally considered to be a factor of prime importance for gas exchange processes not only in the open ocean, but also in lakes. Because of the established non-linear form of the dependence of the gas transfer velocity on wind speed at small space and time scales (Fig. 1), it follows that knowledge of the wind-speed probability distribution should yield a better estimate of the mean gas transfer velocity at larger scales than knowledge of the mean wind speed alone. The analytical representation of wind-speed probabilities by the Weibull distribution allows the empirical characterization of a scalar wind field on the basis of two Weibull parameters. Combining the Weibull wind-speed distribution with trilinear and power-law expressions for the dependence of the gas transfer velocity on wind speed allows the non-linear wind effect to be taken into account and results in eqs. (13) and (17), respectively, for the mean gas transfer velocity. The non-linear wind effect is unlikely to account for an increase in the mean transfer velocity of more than $100 \%$ over the value obtained when this effect is neglected, implying that large discrepancies between measured and computed transfer velocities cannot be accounted for solely by this effect. Nevertheless, incorporation of this effect into models of gas exchange, both in lakes and in the ocean, should improve the accuracy of mean transfer velocity estimates.

Mean winter wind speeds ranging from $1.6-2.8 \mathrm{~m} \mathrm{~s}^{-1}$ and $\mathrm{O}_{2}$ transfer velocities of $0.6-1.0 \mathrm{~m} \mathrm{~d}^{-1}$ appear to be representative of medium-sized subalpine Swiss lakes (larger lakes tend to exhibit higher rates of gas exchange according to Jähne et al., 1984b). As is apparent from Fig. 1, neither the trilinear relationship of Liss and Merlivat (1986) nor the power-law relationship of Wanninkhof and Bliven (1991) predict gas transfer velocities even approaching this magnitude at such low wind speeds. In the specific example referred to here (Aegerisee), it is also apparent that the discrepancy between a mean wind speed of $1.8 \mathrm{~m} \mathrm{~s}^{-1}$ and a mean $\mathrm{O}_{2}$ transfer velocity of $0.83 \mathrm{~m} \mathrm{~d}^{-1}$ cannot be accounted for solely by non-linear wind effects. Postulating a constant non-zero gas transfer velocity of the magnitude found by Liss et al. (1981) at very low wind speeds improves the estimate somewhat, but in order to obtain mean gas transfer velocities as high as those observed in the field, a much higher value for this constant must be assumed. This, however, would be tantamount to rejecting the hypothesis that the instantaneous wind speed plays a significant rôle in determining the gas transfer velocity in lakes such as Aegerisee.

In any event, it is apparent from the present study that neither the trilinear relationship of Liss and Merlivat (1986) nor the power-law relationship of Wanninkhof and Bliven (1991), even when modified to take into account the non-linear wind effect (Fig. 4), suffices to predict gas transfer velocities in lakes at low mean wind speeds without further modification to account for anomalously high rates of gas exchange at low instantaneous wind speeds. This study also suggests that instantaneous wind influence on lake oxygenation under the meteorological conditions prevailing in central Europe (especially in mountainous areas, where small or medium-sized lakes are afforded a certain degree of protection from the wind) may in general be of much less importance than previously assumed. This is however unlikely to be the case in flatter areas with relatively high mean wind speeds, and almost certainly does not apply to oceanic areas.

In general, it should not be forgotten that a natural water body is in a dynamic state even when the instantaneous wind speed is zero. Thus the effect of a wind event in the laboratory is essentially short-term; in the field, however, a wind event may have a long-term influence on gas exchange which, for reasons of scale, cannot be reproduced in the laboratory.

\section{Acknowledgments}

We are indebted to Mr. C. Blattmann for permission to install an anemometer in the Oberägeri bathing facility, to Dr. U. Rütter, Ms. U. Steinemann and Mr. R. Mosimann for their aid in installing and removing the anemometer and associated gear, to Ms. C. Friedl and Ms. C. Romero for their help with the production measurements, and to Prof. J. Gatt for his valuable 
comments and suggestions. Wind data from the Zugerberg climatological station were obtained through the good offices of Mr. W. Eckert of the
Swiss Meteorological Office. This work was supported in part by Swiss National Science Foundation grants 3.125-0.81 and 20-27751.89.

\section{REFERENCES}

Abramowitz, M. and Stegun, I. A., eds. 1970. Handbook of mathematical functions with formulas, graphs and mathematical tables. New York: Dover, 1046 p.

Bossard, P. and Gächter, R. 1981. Methan- und Sauerstoffhaushalt im mesotrophen Lungernsee. Schweiz. Z. Hydrol. 43, 219-252.

Boutin, J. and Etcheto, J. 1991. Intrinsic error in the airsea $\mathrm{CO}_{2}$ exchange coefficient resulting from the use of satellite wind speeds. Tellus 43B, 236-246.

Broecker, H. C. and Siems, W. 1984. The role of bubbles for gas transfer from water to air at higher windspeeds. Experiments in the wind-wave facility in Hamburg. In: Gas transfer at water surfaces (W. Brutsaert and G. H. Jirka, eds. ), 229-236. Dordrecht: D. Reidel Publ. Co.

Broecker, H. C., Petermann, J. and Siems, W. 1978. The influence of wind on $\mathrm{CO}_{2}$-exchange in a wind-wave tunnel, including the effects of monolayers. J. Mar. Res. 36, 595-610.

Broecker, W. S. and Peng, T.-H. 1974. Gas exchange rates between air and sea. Tellus 26, 21-35.

Conradsen, K., Nielsen, L. B. and Prahm, L. P. 1984. Review of Weibull statistics for estimation of wind speed distributions. J. Appl. Meteorol. 23, 1173-1183.

Davenport, A. G. 1967. The dependence of wind loads on meteorological parameters. Proc. Int. Res. Sem. on Wind Effects on Buildings and Structures. Ottawa, 19-82.

Downing, A. L. and Truesdale, G. A. 1955. Some factors affecting the rate of solution of oxygen in water. J. Appl. Chem. 5, 570-581.

Emerson, S. R. 1975. Gas exchange rates in small Canadian Shield lakes. Limnol. Oceanogr. 20, 754-761.

Erickson, D. J., III 1989. Variations in the global air-sea transfer velocity field of $\mathrm{CO}_{2}$. Global Biogeochem. Cycles 3, 37-41.

Erickson, D. J., III and Taylor, J. A. 1989. Non-Weibull behaviour observed in a model-generated global surface wind field frequency distribution. J. Geophys. Res. 94C, 12693-12698.

Etcheto, J. and Merlivat, L. 1988. Satellite determination of the carbon dioxide exchange coefficient at the ocean-atmosphere interface: a first step. J. Geophys. Res. 93C, 15669-15678.

Etcheto, J., Boutin, J. and Merlivat, L. 1991. Seasonal variation of the $\mathrm{CO}_{2}$ exchange coefficient over the global ocean using satellite wind speed measurements. Tellus 43B, 247-255.

Hartmann, B. and Hammond, D. E. 1984. Gas exchange rates across the sediment-water and air-water inter- faces in South San Francisco Bay. J. Geophys. Res. $89 C, 3593-3603$.

Hasse, L. 1990. On the mechanism of gas exchange at the air-sea interface. Tellus 42B, 250-253.

Hasse, L. and Liss, P. S. 1980. Gas exchange across the air-sea interface. Tellus 32, 470-481.

Hennessey, J. P., Jr. 1977. Some aspects of wind power statistics. J. Appl. Meteorol. 16, 119-128.

Hoover, T. E. and Berkshire, D. C. 1969. Effects of hydration on carbon dioxide exchange across an air-water interface. J. Geophys. Res. 74, 456-464.

Imboden, D. M., Lemmin, U., Joller, T. and Schurter, M. 1983. Mixing processes in lakes: mechanisms and ecological relevance. Schweiz. Z. Hydrol. 45, 11-44.

Imboden, D. M., Stotz, B. and Wüest, A. 1988. Hypolimnic mixing in a deep alpine lake and the role of a storm event. Verh. Internat. Verein. Limnol. 23, 67-73.

Inoue, Y. H. and Sugimura, Y. 1992. Variations and distributions of $\mathrm{CO}_{2}$ in and over the equatorial Pacific during the period from the $1986 / 88$ El Niño event to the $1988 / 89 \mathrm{La}$ Niña event. Tellus $44 B, 1-22$.

Jähne, B., Münnich, K. O. and Siegenthaler, U. 1979. Measurements of gas exchange and momentum transfer in a circular wind-water tunnel. Tellus 31, 321-329.

Jähne, B., Huber, W., Dutzi, A., Wais, T. and Ilmberger, J. 1984a. Wind/wave-tunnel experiment on the Schmidt number and wave field dependence of air/ water gas exchange. In: Gas transfer at water surfaces (W. Brutsaert and G. H. Jirka, eds.), 303-309. Dordrecht: D. Reidel Publ. Co.

Jähne, B., Fischer, K. H., Ilmberger, J., Libner, P., Weiss, W., Imboden, D., Lemmin, U. and Jaquet, J. M. 1984b. Parameterization of air/lake gas exchange. In: Gas transfer at water surfaces (W. Brutsaert and $\mathbf{G}$. $\mathbf{H}$. Jirka, eds. ), 459-466. Dordrecht: D. Reidel Publ. Co.

Jähne, B., Wais, T., Memery, L., Caulliez, G., Merlivat, L., Münnich, K. O. and Coantic, M. 1985. He and Rn gas exchange experiments in the large wind-wave facility of IMST. J. Geophys. Res. 90C, 11989-11997.

Jähne, B., Münnich, K. O., Bösinger, R., Dutzi, A., Huber, W. and Libner, P. 1987. On the parameters influencing air-water gas exchange. J. Geophys. Res. 92C, 1937-1949.

Justus, C. G., Hargraves, W. R. and Yalcin, A. 1976. Nationwide assessment of potential output from windpowered generators. J. Appl. Meteor. 15, 673-678.

Justus, C. G., Hargraves, W. R., Mikhail, A. and Graber, D. 1978. Methods for estimating wind speed frequency distributions. J. Appl. Meteorol. 17, 350-353.

Kanwisher, J. 1963. On the exchange of gases between 
the atmosphere and the sea. Deep-Sea Res. 10, 195-207.

Lasenby, D. C. 1975. Development of oxygen deficits in 14 southern Ontario lakes. Limnol. Oceanogr. 20, 993-999.

Ledwell, J. J. 1984. The variation of the gas transfer coefficient with molecular diffusivity. In: Gas transfer at water surfaces (W. Brutsaert and G. H. Jirka, eds.), 293-302. Dordrecht: D. Reidel Publ. Co.

Lewis, W. K. and Whitman, W. G. 1924. Principles of gas absorption. Indust. Eng. Chem. 16, 1215-1224.

Liss, P. S. 1973. Processes of gas exchange across an air-water interface. Deep-Sea Res. 20, 221-238.

Liss, P. S. 1983. Gas transfer: experiments and geochemical implications. In: Air-sea exchange of gases and particles (P. S. Liss and W. G. N. Slinn, eds.), 241-298. Dordrecht: D. Reidel Publ. Co.

Liss, P. S., Balls, P. W., Martinelli, F. N. and Coantic, M. 1981. The effect of evaporation and condensation on gas transfer across an air-water interface. Oceanol. Acta 4, 129-138.

Liss, P. S. and Merlivat, L. 1986. Air-sea gas exchange rates: introduction and synthesis. In: The role of airsea exchange in geochemical cycling ( $\mathrm{P}$. Buat-Ménard, ed.), 113-127. Dordrecht: D. Reidel Publ. Co.

Livingstone, D. M. 1988. Einfluss externer physikalischer Faktoren auf das Sauerstoffregime des Aegerisees. PhD dissertation, Univ. Zürich, 273 pp.

Livingstone, D. M. 1991. The diel oxygen cycle in three subalpine Swiss streams. Arch. Hydrobiol. 120, $457-479$.

Livingstone, D. M. and Imboden, D. M. 1989. Annual heat balance and equilibrium temperature of Lake Aegeri, Switzerland. Aquat. Sci. 51, 351-369.

Luna, R. E. and Church, H. W. 1974. Estimation of long-term concentrations using a "universal" wind speed distribution. J. Appl. Meteor, 13, 910-916.

Mackay, D. 1985. Air/water exchange coefficients. In: Environmental exposure from chemicals, vol. I (W. B. Neely and G. E. Blau, eds.), 91-108. Boca Raton: CRC Press.

Marti, D. E. and Imboden, D. M. 1986. Thermische Energieflüsse an der Wasseroberfläche: Beispiel Sempachersee. Schweiz. Z. Hydrol. 48, 196-229.

Merlivat, L. and Memery, L. 1983. Gas exchange across an air-water interface: experimental results and modeling of bubble contribution to transfer. J. Geophys. Res. 88, 707-724.

Münnich, K. O., Clarke, W. B., Fischer, K. H., Flothmann, D., Kromer, B., Roether, W., Siegenthaler, U., Top, Z. and Weiss, W. 1978. Gas exchange and evaporation studies in a circular wind tunnel, continuous radon-222 measurements at sea, and tritium/ helium-3 measurements in a lake. In: Turbulent fluxes through the sea surface, wave dynamics, and prediction. NATO Conference Series, $V$, Air-sea interactions, Vol. I (A. Favre and K. Hasselmann, eds.), 151-166. New York: Plenum Press.

Orlenko, L. R. 1968. Wind and its technical aspects.
Proc. Symp. on Urban Climates and Building Climatology, Brussels, Vol. II, 37-56. WMO Tech. Note No. 109. WMO No. 225.TP.142.

Örn, C. G. 1980. Die Sauerstoffverhältnisse im Zürichsee (Untersee) von 1937 bis 1975 und ihre Beeinflussung durch meteorologische Faktoren. Vierteljahrsschr. naturf. Ges. Zürich 125, 259-364.

Pavia, E. G. and O'Brien, J. J. 1986. Weibull statistics of wind speed over the ocean. J. Clim. Appl. Meteorol. 25, 1324-1332.

Peng, T.-H., Takahashi, T. and Broecker, W. S. 1974. Surface radon measurements in the North Pacific Ocean Station PAPA. J. Geophys. Res. 79, 1772-1780.

Peng, T.-H., Broecker, W. S., Mathieu, G. G., Li, Y.-H. and Bainbridge, A. E. 1979. Radon evasion rates in the Atlantic and Pacific Oceans as determined during the Geosecs program. J. Geophys. Res. 84C, 2471-2486.

Peng, T.-H. and Broecker, W. S. 1980. Gas exchange rates for three closed-basin lakes. Limnol. Oceanogr. 25, 789-796.

Quinn, J. A. and Otto, N. C. 1971. Carbon dioxide exchange at the air-sea interface: flux augmentation by chemical reaction. J. Geophys. Res. 76, 1539-1549.

Ravenis, J. V. J., II 1964. Estimating Weibull distribution parameters. Electro-Technology 73, 46-54.

Smethie, W. M., Jr., Takahashi, T., Chipman, D. W. and Ledwell, J. R. 1985. Gas exchange and $\mathrm{CO}_{2}$ flux in the tropical Atlantic Ocean determined from ${ }^{222} \mathrm{Rn}$ and pCO ${ }_{2}$ measurements. J. Geophys. Res. 90C, 7005-7022.

Spitzer, W. S. and Jenkins, W. J. 1989. Rates of vertical mixing, gas exchange and new production: estimates from seasonal gas cycles in the upper ocean near Bermuda. J. Mar. Res. 47, 169-196.

Stewart, D. A. and Essenwanger, O. M. 1978. Frequency distribution of wind speed near the surface. J. Appl. Meteorol. 17, 1633-1642.

Takle, E. S. and Brown, J. M. 1978. Note on the use of Weibull statistics to characterize wind-speed data. J. Appl. Meteorol. 17, 556-559.

Thorpe, S. A. 1982 . On the clouds of bubbles formed by breaking wind-waves in deep water, and their role in air-sea gas transfer. Phil. Trans. R. Soc. Lond. A 304, 155-210.

Tsunogai, S. and Tanaka, N. 1980. Flux of oxygen across the air-sea interface as determined by the analysis of dissolved components in sea water. Geochem. J. 14, 227-234.

Tuller, S. E. and Brett, A. C. 1984. The characteristics of wind velocity that favor the fitting of a Weibull distribution in wind speed analysis. J. Appl. Meteorol. 23, 124-134.

Upstill-Goddard, R. C., Watson, A. J., Liss, P. S. and Liddicoat, M. I. 1990. Gas transfer velocities in lakes measured with $\mathrm{SF}_{6}$. Tellus 42B, 364-377.

Van der Auwera, L., de Meyer, F. and Malat, L. M. 1980. The use of the Weibull three-parameter model for estimating mean wind power densities. J. Appl. Meteorol. 19, 819-825.

Wanninkhof, R. 1992. Relationship between gas 
exchange and wind speed over the ocean. J. Geophys. Res. 97C, 7373-7381.

Wanninkhof, R., Ledwell, J. R. and Broecker, W. S. 1985. Gas exchange, wind speed relation measured with sulfur hexafluoride on a lake. Science 227, 1224-1226.

Wanninkhof, R., Ledwell, J. R., Broecker, W. S. and Hamilton, M. 1987. Gas exchange on Mono Lake and Crowley Lake, California. J. Geophys. Res. 92C, 14567-14580.

Wanninkhof, R. H. and Bliven, L. F. 1991. Relationship between gas exchange, wind speed, and radar backscatter in a large wind-wave tank. J. Geophys. Res. 96C, 2785-2796.

Wanninkhof, R., Ledwell, J. R. and Crucius, J. 1991. Gas transfer velocities on lakes measured with sulfur hexafluoride. Proc. 2nd internat. symp. on gas transfer at water surfaces, Minneapolis (Eds. S. C. Wilhelms and J. S. Gulliver), 441-458.
Watson, A. J., Upstill-Goddard, R. C. and Liss, P. S. 1991. Air-sea gas exchange in rough and stormy seas measured by a dual-tracer technique. Nature 349 , 145-147.

Weibull, W. 1951. A statistical distribution function of wide applicability. J. Appl. Mech. 18, 293-297.

Whitman, W. G. 1923. A preliminary experimental confirmation of the two-film theory of gas absorption. It seems to explain satisfactorily the well-recognized differences of absorption rate for varying concentrations. Chem. Metall. Eng. 29, 146-148.

Widger, W. K., Jr. 1977. Estimations of wind speed frequency distributions using only the monthly average and fastest mile data. J. Appl. Meteor. 16, 244-247.

Yu, S. L., Hamrick, J. M. and Lee, D.-S. 1984. Wind effects on air-water oxygen transfer in a lake. In: Gas transfer at water surfaces (W. Brutsaert and G. H. Jirka, eds. ), 357-367. Dordrecht: D. Reidel Publ. Co. 